\title{
ONLY TIME WILL TELL: THE CHANGING RELATIONSHIPS BETWEEN LMX, JOB PERFORMANCE, AND JUSTICE
}

\author{
Sanghee Park (spark@smlr.rutgers.edu), Rutgers University \\ Michael C. Sturman (mcs5@ cornell.edu), Cornell University \\ Chelsea Vanderpool (cvanderpool@govst.edu), Governors State University \\ Elisa Chan (elisa.chan@ehl.ch), Ecole hôtelière de Lausanne
}




\begin{abstract}
Although it has been argued that LMX is a phenomenon that develops over time, the existing LMX literature is largely cross-sectional in nature. Yet, there is a great need for unraveling how LMX develops over time. To address this issue in the LMX literature, we examine the relationships of LMX with two variables known for changing over time: job performance and justice perceptions. On the basis of current empirical findings, a simulation deductively shows that LMX develops over time, but differently in early stages versus more mature stages. Our findings also indicate that performance and justice trends affect LMX. Implications for LMX theory, and for longitudinal research on LMX, performance, and justice are discussed.
\end{abstract}

\title{
Keywords:
}

LMX; Dynamic performance; Performance trend; Organizational Justice over time 
Leader-Member Exchange (LMX) theory purports that leaders develop different quality relationships with different subordinates through social exchanges (Dulebohn, Bommer, Liden, Brouer, \& Ferris, 2012; Graen \& Scandura, 1987; Graen \& Uhl-Bien, 1995; Liden \& Graen, 1980). This development is inherently a process that occurs over time (Day, 2014). LMX theory predicts that, at different stages of a leader-member relationship, antecedents of LMX can play different roles and change in terms of their relative importance (Bauer \& Green, 1996; Graen \& Scandura, 1987). Researchers have expressed the need for greater theoretical development and testing, and longitudinal research in particular, to enhance our understanding of cause-effect mechanisms of LMX development beyond the traditional focus on outcomes of LMX (e.g., Day, 2014; Dulebohn et al., 2012; Ilies, Nahrgang, \& Morgeson, 2007; Kacmar, Witt, Zivnuska, \& Gully, 2003; Ployhart, Holtz, \& Bliese, 2002; Sparrowe, Soetjipto, \& Kraimer, 2006; Wilson, Sin, \& Conlon, 2010). Considering the role of time in LMX theory presents the opportunity to test important theoretical questions about LMX development—how the influence of LMX antecedents change, not only in early stages, but also during more mature stages; and how LMX interacts with key variables over time - that can lead to building better theory in the LMX literature (cf., Mitchell \& James, 2001). The main purpose of this study is to contribute to LMX theory by advancing our understanding of how key relationships with LMX develop over time.

In our study, we focus on two specific factors that are key dynamic correlates of LMX: job performance and organizational justice. Both job performance and organizational justice have been shown to have important relationships with LMX, and they are two of the most studied correlates of LMX (Dulebohn et al., 2012). Furthermore, researchers have begun to uncover the dynamics of these constructs in their own right. Specifically, there is a large body of research considering the dynamic nature of job performance (Beal, Weiss, Barros, \& MacDermid, 2005; 
Deadrick, Bennett, \& Russell, 1997; Sturman, 2007; Sturman, Cheramie, \& Cashen, 2005) as well as a developing body of research on the dynamic nature of justice, both as an isolated construct (Hausknecht, Sturman, \& Roberson, 2011; Lilly, Virick, \& Hadani, 2010; Loi, Yang, \& Diefendorff, 2009) and as it relates to LMX (Wilson, 2011). Thus, examining how two such dynamic variables relate to LMX development allows us to understand the role of time in the prediction and development of LMX. Knowledge gained from understanding the longitudinal nature of the specific covariates of LMX can provide insights into how LMX develops over time.

The lack of research on LMX development, though, has not been so limited because of any lack of recognition of its importance; rather, quite practically, collecting longitudinal, withinperson data about a leader-member relationship is highly problematic (Gooty \& Yammarino, 2011; Krasikova \& LeBreton, 2012; Nahrgang, Morgeson, \& Ilies, 2009). The issue makes any sort of long-term empirical investigation of LMX development (let alone within-person analyses) extremely difficult with traditional (e.g., experiment, field study, or survey) methodologies. Thus, this study also extends LMX research by applying a different methodological approach that can overcome many of the issues associated with conventional methods, and particularly the design and execution of longitudinal studies: simulation.

Our simulation approach, while relatively novel, is actually not radically different from existing methodologies. The approach we will employ uses a combination of meta-analysis and agent-based modeling. We conduct a meta-analysis amongst our variables of interest to create a correlation matrix, use simulation to create a dataset that conforms to this correlation matrix, and then "age" employees over many time periods based on the meta-analytically derived information. This approach is thus similar to the approach of combining meta-analysis and structural equations modeling (SEM) (e.g., de Wit, Greer, \& Jehn, 2012; Jiang, Liu, McKay, Lee, 
\& Mitchell, 2012; Thatcher \& Patel, 2011; Viswesvaran \& Ones, 1995), in that we first look to the existing literature to find estimates of current relationships and then base subsequent analyses on these estimates. At the same time, the simulation approach that we conducted is also different from the combination of meta-analyses and SEM, in that whereas the meta-analysis/SEM approach performs tests based on just the matrix of correlates that were gathered, the metaanalysis/simulation approach we employ generates a longitudinal dataset based on the correlates and then analyses the resultant dataset. Note that, unlike some other simulation approaches (cf., Harrison, Lin, Carroll, \& Carley, 2007), we do not model the specific causal process, but rather the correlates of our key variables that should capture and represent the results of causal processes. Ultimately, we will be testing if the hypotheses we develop are consistent with the current existing literature on LMX. Using simulation — and grounding our method on the LMX, justice, and performance literatures - we provide a detailed look into the long-term within-person processes associated with LMX. Our simulation methodology provides a means to test LMX theory and identify crucial areas for future empirical research.

Our research contributes to the LMX literature in several ways. First, we consider the role of time and LMX from a long-term perspective. The foundational work on LMX emerged from work based on social exchange theory (Blau, 1964), and this exchange-based dyadic relationship by its very nature inherently involves time (e.g., Day, 2014; Hu \& Liden, 2013; Ilies et al., 2007): relationships between leaders and their subordinates develop and change over a period of time. While there are now a handful of notable longitudinal studies, most research in the area has been cross-sectional (e.g., Dulebohn et al., 2012; Gerstner \& Day, 1997; Liden, Wayne, \& Stilwell, 1993; Shamir, 2011), or short-term (i.e., under one year) studies (e.g., Bauer \& Green, 1996; Liden et al., 1993; Nahrgang et al., 2009). While there are career-long generalizations and 
implications that emerge from LMX research (Erdogan, Kraimer, \& Liden, 2004; Scandura \& Schriesheim, 1994; Thomas \& Lankau, 2009; Wakabayashi \& Graen, 1984, 1989), the disconnection between the theory and empirical tests limits the advancement of our knowledge and understanding of LMX (Pitariu \& Polyhart, 2010; Ployhart et al., 2002; Shamir, 2011). In this paper, we rely on prior theory, combined with existing empirical evidence which includes both cross-sectional and largely short-term longitudinal studies, to derive theoretically-based hypotheses with regard to how LMX develops over time within individuals.

Second, this study tests predictions about LMX development by considering the trajectory of individuals' LMX perceptions over time (i.e., by taking a within-person perspective). To date, there is still a lack of longitudinal research to consider LMX development from a within-person perspective (for a notable exception, see Nahrgang et al., 2009). Most previous research has generally tested LMX theories by investigating across-person relationships, such as crosssectional covariates of LMX or how early expectations or employee characteristics predict LMX levels (i.e., in-groups/high quality relationships vs. out-groups/low quality relationships) in later time periods (e.g., Bauer \& Green, 1996; Dansereau, Graen, \& Haga, 1975; Gerstner \& Day, 1997; Graen \& Uhl-Bien, 1995; Liden et al., 1993; Wakabayashi, Graen, Graen, \& Graen, 1988). Given the inherent temporal nature of LMX theory, understanding LMX development from a withinperson perspective is critical to test and develop LMX theory (Nahrgang et al., 2009). This present study investigates how two dynamic constructs (performance and justice), as antecedents and outcomes of LMX, relate to within-person changes in the level of LMX. More specifically, we develop and test LMX theory to form hypotheses about how job performance and justice affect future levels of LMX, as well as how changes in performance and justice trajectories predict future LMX. 
Third, our research contributes to the LMX field, and perhaps more generally to OB and HR research, by investigating LMX development over time using a new method. Simulation, in general, is relatively rare in management research (Davis, Eisenhardt, \& Bingham, 2007; Harrison et al., 2007; Koslowski, Chao, Grand, Braun, \& Kuljanin, 2013; Weinhardt \& Vancouver, 2012), and the approach we employ in this paper is entirely new. Our approach uses existing empirical results (combined with meta-analysis when possible) to describe relationships between key variables both cross-sectionally (i.e., correlations of between-person relationships) and over a short (i.e., 3-month) longitudinal span (i.e., correlations of short-term within-person relationships). By assuming that this correlational structure is stable (i.e., these correlations do not change with time), and that these correlations capture the effects of the causal mechanisms that influence how LMX, justice, and job performance change with time, we test heretofore untested predictions about LMX development. In short, by combining meta-analysis with simulation, we demonstrate a means to see if the existing literature has temporal implications that are not readily apparent by examining cross-sectional relationships, short-term longitudinal relationships, or correlations with temporal variables like tenure.

\section{LONGITUDINAL INSIGHTS INTO LEADER-MEMBER EXCHANGE}

\section{What We Know of the Leader-Member Exchange over Time}

Research on LMX development argues that LMX relationships advance through various stages of interactions across time (Bauer \& Green, 1996; Dienesch \& Liden, 1986; Nahrgang et al., 2009). In particular, Graen and Scandura (1987) theorized the presence of three stages of "dyadic organizing": the role taking stage, the role making stage, and the role routinization stage. In the early stage, a leader may want to see how much his/her subordinates make an effort to achieve their goals and perform their jobs (Bauer \& Green, 1996; Dienesch \& Liden, 1986; Graen 
\& Scandura, 1987; Graen \& Uhl-Bien, 1995; Liden et al., 1993). The leader decides what to delegate and makes judgments of current experiences about their subordinates based on past experiences and information. Liden et al. (1993) applied "the Pygmalion effect" to the development of LMX. That is, the reciprocal relationship develops as leaders' expectations and their subordinates' internalization of the expectations interact. Based on subordinates' performance at the early stage of their relationship, supervisors' evaluations, and subordinates' assessments of leaders' behaviors, individuals form their LMX perceptions (Dienesch \& Liden, 1986; Nahrgang et al., 2009). After the early stage, the dyadic relationship evolves through performance evaluations as well as continuous expectations and behaviors of both parties, but the levels of LMX during these early states do certainly relate to later levels of LMX. Indeed, Wakabayashi et al. (1988) examined college graduates' management progress in a Japanese corporation by tracking them for 13 years. The results showed that early stages of the dyadic work relationships were related to LMX quality up to 13 years later. They also found that, while LMX changes over time, future outcomes can be predicted. Thus, the incremental and cumulative effects of leader delegation and subordinates' performance are key to understanding the longitudinal development of LMX relationships (Bauer \& Green, 1996). Through the delegation process, mutual reciprocity is also developed (Bauer \& Green, 1996; Dansereau et al., 1975).

Although we note a lack of within-person longitudinal investigations of LMX, a notable exception is the work by Narhrgang et al. (2009). In their study, the authors collected data from an experiential undergraduate class over eight weeks to assess LMX development. The Nahrgang et al. (2009) study provided some important insights confirming and expanding LMX theory. First, their study empirically confirmed the across-person variability in the level and trend in LMX relationships. Second, they found that despite the predicted variability, the average LMX 
relationship improved with time. This positive trend was found regardless of whether the relationship was of initially high or low quality. Third, using their within-subjects design, they also found that early factors in the LMX relationship affect later levels of the relationship. That is, they provided a partial test of Dienesch and Liden's (1986) model, showing that initial characteristics of both the leader and subordinate, such as personality and job performance, affected the later level and development of the relationship.

\section{Our Focal Correlates of LMX}

The long history of LMX research has afforded many opportunities to consider antecedents and outcomes of leader-member relationships. The most recent meta-analysis on the subject (Dulebohn et al., 2012) identified 247 studies and empirically reviewed 37 different correlates. The focus of our study, though, is on the role of time in the prediction of LMX and how relationships with LMX change with time. We therefore focus on two key correlates of LMX that (1) have important relationships with LMX, and (2) have received attention in their own right regarding their dynamic properties. Thus, we examine job performance and organizational justice.

Job performance is the most-often studied correlate of LMX (Dulebohn et al., 2012). It is clearly a key antecedent and a consequence of the LMX relationship and, due to this role, is often involved in theoretical models of LMX (e.g., Dienesch \& Liden, 1986; Dulebohn et al., 2012; Liden et al., 1993). Job performance has also received extensive attention regarding its own dynamic nature (cf., Sturman, 2007). Research has shown that job performance does indeed change across time, and it is influenced by both stable factors (e.g., cognitive ability, personality) and unstable factors (e.g., job knowledge, motivation, and leadership) (Day, Sin, \& Chen, 2004; Dudley, Orvis, Lebiecki, \& Cortina, 2006; Sturman, 2007). In the context of LMX relationships, a variety of changes of the unstable factors (e.g., leadership) that happen to individuals would 
facilitate performance changes over time. As a result, both parties continue to develop other attitudinal and behavioral factors such as trust and support along with each other's job performance and following performance evaluations (e.g., Nahrgang et al., 2009). As such, prior research noted that subordinates' job performance is the main cause of differential LMX relationships at early stages, which in turn should affect the LMX relationship at later stages (e.g., Bauer \& Green, 1996; Dienesch \& Liden, 1986; Nahrgang et al., 2009). Given the critical role that performance plays with LMX, understanding LMX development over time must be considered in conjunction with the dynamic characteristics of job performance.

LMX theory has also long recognized the role of equity in the development of LMX (e.g., Bauer \& Green, 1996; Dienesch \& Liden, 1986; Graen \& Scandura, 1987). Justice perceptions in organizations are defined as employees' perceptions about how fairly they are treated by their direct supervisors and/or their organization (Greenberg, 1996). Organizational justice provides a valuable perspective for understanding how subordinates' LMX perceptions develop in terms of "fair treatment" and "fair exchange" issues (Scandura, 1999). Indeed, the main premise of LMX theory — that there are differentiated groups (i.e., in-groups and out-groups) based on the quality of LMX relationships-is inconsistent with "norms of equality" (Scandura, 1999, p. 26). As such, because justice is socially constructed (Colquitt, Conlon, Wesson, Porter, \& Ng, 2001), and social exchange theory provides the basis for LMX theory (Dienesch \& Liden, 1986; Eisenberger, Shoss, Karagonlar, Gonzalez-Morales, Wickham, \& Buffardi, 2013), a subordinate's justice perceptions play an important role for understanding how that individual's LMX perceptions develop (Erdogan, Liden, \& Kraimer, 2006; Masterson, Lewis, Goldman, \& Talor, 2000; Wayne, Shore, Bommer, \& Tetrick, 2002). Justice also has an extensive literature in relation to performance (e.g., Cohen-Charash \& Spector, 2001; Colquitt et al., 2001). Drawing on equity 
theory and social exchange theory, empirical evidence shows that organizational justice is related to employees' performance (Cohen-Charash \& Spector, 2001; Colquitt et al., 2001) and is important for understanding how job performance and LMX relate (Cohen-Charash \& Spector, 2001; Masterson et al., 2000). Thus, employees' perceived fairness of their supervisors also plays a significant role in subsequent LMX relationships (Erdogan et al., 2006; Masterson et al., 2000; Wayne et al., 2002).

As George and Jones (2000) noted that "time is intimately bound up with the content of human experience in that the past and future are reflected in the present.... the future is embedded in the present in terms of expectations, possibilities, and strivings" (p. 659), these three constructs are inherently connected in a web of time because LMX, job performance, and organizational justice change over time and are interrelated. That is, LMX and performance are related because of a norm of reciprocity, with resources and support coming from the supervisor to the employee, and the employee reciprocating with motivation. As a result, LMX changes should lead to performance changes with time (Nahrgang et al., 2009). At the same time, because performance is dynamic (Sturman, 2007) and some of this dynamism is attributable simply to seemingly random error over time (Sturman et al., 2005), performance changes will also likely alter LMX perceptions. Throughout this process, employees' LMX perceptions will be driven by fairness perceptions of their relationships. Changes in employees' LMX perceptions should then again relate to reciprocity and job performance. This entire dynamic web then recurs. We thus build on the literatures that examine the longitudinal qualities of LMX, job performance, and organizational justice to better understand how key relationships with LMX develop over time. Theoretical Gaps in Our Understanding of the Leader-Member Exchange over Time The effects at different stages of LMX development. Current research provides several 
key insights for understanding LMX development over time. There are postulations about different stages of LMX, some empirical evidence of LMX over time, and clear connections with constructs that also change over time. Yet, several key theoretical questions remain untested.

One gap in the LMX literature involves understanding individuals' developmental differences (within-person processes) between early LMX relationships and LMX development during more "mature" states (Gerstner \& Day, 1997; Graen \& Uhl-Bien, 1995; Nahrgang et al., 2009; Shamir, 2011). In part, this is because previous LMX research could not examine what occurs over the latter time frame due to the difficulty of collecting appropriate data. Nonetheless, insights and extrapolations from past research suggest that there are key differences regarding employees' LMX perceptions between employees in these two states. For example, because newcomers to an organization may require more information and support, they are effectively participating in two interrelated processes: socialization into the organization, and the development of a new LMX relationship (Ashford \& Black, 1996; Dienesch \& Liden, 1986; Feldman \& Brett, 1983; Sluss \& Thompson, 2012). Dienesch and Liden (1986) argued that "the distinction between new hire and incumbent is an individual characteristic that may have important implications" for their model of the LMX developmental process (p. 628). Both leaders and subordinates develop and change their relationships with increasing experience, as this experience shapes how they view and interpret the relationship. Indeed, existing short-term longitudinal research shows that LMX continues to develop as the variables that affect LMX interact and accumulate over time (Gerstner \& Day, 1997; Nahrgang et al., 2009).

In the early stages of LMX, both parties are forming impressions based on limited information. Through day-to-day interactions, including informal conversations and shared events, the behaviors of two people influence each other and the two individuals continue to 
conceptualize the incremental process (Graen \& Scandura, 1987). At this time, early anchoring events play a large part in shaping early judgments and evaluations (Ballinger \& Rockmann, 2010). In the role taking stages, leaders are seeing how subordinates perform through different levels of delegations based on "idiosyncratic reasons such as perceived similarity, liking, and/or other subordinate characteristics" (Sluss \& Thompson, 2012, p.116) in order to form judgments, and subordinates are also making judgments based on their leaders' feedback and employees' reactions to leader behaviors (Graen \& Scandura, 1987; Ployhart et al., 2002; Sluss \& Thompson, 2012). Thus, during this early stage, supervisor evaluation of subordinates' performance ratings and subordinates' justice perceptions toward their immediate supervisors should play an important role in the development of employees' LMX perceptions (Dienesch \& Liden, 1986; Nahrgang et al., 2009).

In more mature stages, such as during the role routinization stage, because individuals have had time to observe and react to the other member in their dyads, the likelihood of anchoring events should be smaller in more established relationships (Ballinger \& Rockmann, 2010). Performance and justice perceptions should be less influential in affecting LMX perceptions, although they should still remain relevant. In other words, because of experiences gained over time, new job performance ratings and new perceptions of organizational justice from the LMX interactions should become less influential as dyadic tenure increases. We therefore hypothesize Hypothesis 1: The effect of justice on the future level of LMX is negatively moderated by tenure, such that the effect is weaker (i.e., less positive) when tenure is high than when it is low.

Hypothesis 2: The effect of job performance on the future level of LMX is negatively moderated by tenure, such that the effect is weaker (i.e., less positive) when tenure is high 
than when it is low.

The different stages of LMX development should also change the relationships of LMX with subsequent justice and performance. As we hypothesized above, in early stages of LMX development, LMX may play a minimal role for influencing subsequent performance and justice perceptions when subordinates are still forming their LMX perceptions. That is, during this roletaking stage, while LMX is being informed by job performance ratings and justice perceptions, LMX should play a minimal role, and thus have weak relationships until the employee's perception of the LMX relationship can be evaluated with greater confidence. Later, in more mature stages, such as during the role routinization stage, as employees' LMX perceptions become based on more information and therefore become more established, the employees' perceptions of their current relationship should become a better determinant of future judgments and allocation decisions; hence, the relationship should become stronger. LMX therefore should actually become more important for predicting these two key outcomes. In other words, the effects of LMX on justice perceptions and job performance should become stronger with time. Thus, we hypothesize

Hypothesis 3: The effect of LMX on the future level of justice perception is positively moderated by tenure, such that the effect is more positive when tenure is high than when it is low.

Hypothesis 4: The effect of LMX on the future level of job performance is positively moderated by tenure, such that the effect is more positive when tenure is high than when it is low.

How LMX develops with performance and justice over time. Prior LMX research has shown that justice, performance, and LMX from one time period should be related to the same set 
of variables in subsequent time periods (e.g., Bauer \& Green, 1996; Nahrgang et al., 2009). Yet, research predicting various attitudes has also shown that attitudes from one time period are not just a function of the most recent level of relevant antecedents, but are also related to changes in those variables (e.g., Ariely \& Carmon, 2000; Chen, Ployhart, Cooper-Thomas, Anderson, \& Bliese, 2011). LMX, as an employee attitude, may likewise be affected by more than just the level of certain antecedents, but also by changes in those antecedents.

Ariely and Carmon (2000) argued that people do not simply average evaluations of past experiences to form current perceptions; rather, individuals rely upon "experience profiles" (i.e., series of episodes of varying intensity) and "extract only a few defining features of these sequences (Gestalt characteristics)" (Ariely \& Carmon, 2000, p.192). To form current perceptions, individuals draw on both static (i.e., end-state evaluations) and dynamic (i.e., trends over time) properties of their past experiences (Hausknecht et al., 2011). People employ summary assessments of their experiences and use information on both the level and trend of these assessments to form current impressions.

Similarly, recent research on job satisfaction (i.e., Chen et al., 2011) combined various theories (i.e., prospect theory, within-person spirals, sense making theory, and conservation of resources theory) to build a theoretical case for how and why attitudes change over time. Although their work was focused on job satisfaction, the theoretical framework is applicable to a host of employee attitudes. From their work, they supported two key propositions that can provide a theoretical basis for understanding employees' perceptions of LMX over time. First, they showed that an employee attitude at an earlier point in time provides a reference point for interpreting that attitude at a later point in time. Second, they demonstrated that attitudes are more salient to the extent that they deviate from their prior levels. Specifically, Chen et al. (2011) 
supported their propositions that job satisfaction levels and trends affected turnover intentions. Similarly, Hausknecht et al. (2011) showed that changes in justice perceptions related to future levels of job satisfaction, organizational commitment, and turnover intentions. Combined, these studies confirm that individuals' perceptions are affected by their interactions with their social contexts, which subsequently affect their behaviors (Dijksterhuis \& Bargh, 2001).

Building upon this research and applying it to the construct of employees' LMX perceptions, this prior work suggests that levels of LMX should be a function of both the level and changes in key attitudinal antecedents. Given the importance of perceptions of organizational justice for LMX (Erdogan et al., 2006; Masterson et al., 2000; Wayne et al., 2002), we should therefore expect that both prior level of justice and justice trends should influence the subsequent level of LMX. We therefore predict,

Hypothesis 5: With the most recent level of organizational justice held constant (i.e., after controlling for its positive effects), organizational justice change is positively associated with the future level of LMX.

The theoretical basis for predicting that positive changes in justice will result in higher levels of employees' LMX perceptions is based on Chen et al.'s (2011) theoretical combination, which specifically relates to the prediction of employee attitudes and is applicable for predicting the effects of justice perceptions. The same theory, though, is not necessarily applicable for predicting effects associated with job performance.

Because LMX relationships inherently involve time, employees' perceptions of LMX necessarily incorporate events that have occurred over their histories with their supervisors. Given the important role of performance for affecting LMX, and given that LMX reflects a relationship that has been built over time, LMX should be influenced by not just the most recent level of 
performance, but also past levels of performance. Unlike with attitudes, though, variation in performance ratings is not positively perceived (Reb \& Greguras, 2010). Although performance variation may not necessarily affect future performance ratings (e.g., Reb \& Cropanzano, 2007), variability in performance ratings may undermine the development of a positive LMX relationship. For example, a consistent high performer is likely to have developed and be maintaining a higher LMX than someone who only recently became a high performer. Accordingly, while high performance should be positively associated with LMX (Dulebohn et al., 2012), after controlling for these effects, changes in performance should be less positively perceived. We therefore predict

Hypothesis 6: With the most recent level of job performance held constant (i.e., after controlling for its positive effects), job performance change is negatively associated with the future level of LMX.

\section{METHODS}

We used computer simulation to examine the longitudinal effects of dynamic performance and justice trends on LMX and vice versa. Simulation provides a means to combine different related areas of research to explore the effects of these areas operationalized simultaneously (Weinhardt \& Vancouver, 2012). It is particularly useful for research, like this present study, which looks at "intertwined processes, nonlinearities, and longitudinal effects" (Davis et al., 2007, p. 482). Although simulation is growing in popularity as a tool for theoretical development in management research (e.g., Finch, Edwards, \& Wallace, 2009; Kozlowski et. al, 2013; Krasikova \& LeBreton, 2012; Vancouver, Weinhardt, \& Schmidt, 2010), the novelty and complexity of the simulation methodology, particularly for theory testing, necessitates that a clear and detailed explanation of the methodology is given. Furthermore, we use a simulation approach that, as far 
as we know, has not been used elsewhere to test theory. In essence, we use simulation to demonstrate the implications of prior empirical findings (largely from meta-analyses, of both cross-sectional and longitudinal relationships), and so our approach is similar to the increasingly common practice of combining meta-analysis and SEM (e.g., de Wit et al., 2012; Jiang et al., 2012; Thatcher \& Patel, 2011; Viswesvaran \& Ones, 1995).

In short, the simulation process that we will employ allows us to deduce relationships, based on what we already know about various interrelated constructs. The computational modeling helps represent what is occurring when piecing together dynamic and complex phenomena from different areas (Vancouver, Tamanini, \& Yoder, 2010). The LMX literature actually lends itself well to this methodology because we are indeed interested in examining the implications associated with the inter-related and dynamic constructs of LMX, job performance, and justice.

We know a significant amount of information about LMX, justice, and job performance; we also know a significant amount about how these variables relate to tenure, and thus have some representation of what happens over time. This includes (a) short-term, longitudinal examinations of LMX (e.g., Bauer \& Green, 1996; Eisenberger et al., 2013; Liden et al., 1993; Nahrgang et al., 2009) and (b) cross-sectional examinations of LMX involving temporal variables, such as dyadic tenure (e.g., Bauer \& Green, 1996; Burton, Sablynski, \& Sekiguchi, 2008; Hooper \& Martin, 2008; Mossholder, Niebuhr, \& Norris, 1990). As noted earlier, we also have information on the dynamics of justice and job performance. But combining these "pieces of the puzzle" together is highly complex. Indeed, work in chaos theory shows that even with just a few simple equations interrelating and operating simultaneously, the combined results can appear highly complex and nearly impossible to predict (cf., Gleick, 1987). There is currently sufficient research to consider 
the relationships between LMX, justice, job performance, and tenure, both cross-sectionally and longitudinally. We need simulation, though, to synthesize these pieces of knowledge and to test their implications for theoretical development (Vancouver et al., 2010).

The simulation process that we employed involves five steps. We describe each of these steps in detail below, but in brief, they involve the following. First, we created a correlation matrix for the variables of interest in this study. This required obtaining information on the strength of relationships between LMX, overall justice, job performance, and tenure from existing empirical research, including gathering information on the relationships amongst these variables both cross-sectionally and longitudinally.

Second, we simulated data over a number of time periods. Ultimately, we generated data over a hypothetical 7-year period (details explained below), with three observations (i.e., a fourmonth interval) per year. Third, we validated the simulation's mechanics by ensuring that the data we created are correlated in the specified manner. And fourth, as the last step, we used the simulated data to test the study's hypotheses. The logic and methodology behind each step are now described.

\section{Determining Effect Sizes}

We determined the relationships between LMX, job performance, tenure, and overall justice to be used in the simulation by combining correlation coefficients from various previous studies. When possible, we employed effect sizes derived from prior meta-analyses (e.g., the cross-sectional relationship between justice and job performance, Cohen-Charash \& Spector, 2001; the cross-sectional relationship between job performance and LMX, Dulebohn et al., 2012; the longitudinal assessment of changes in job performance; Sturman, 2003). Note that Sturman (2003) demonstrated a non-linear relationship between tenure and performance. For this study, we 
computed the average correlation over the range of tenure values we ultimately examined (.28; correlations ranged from .26 to .29). ${ }^{1}$

For other relationships, and particularly those less studied, we relied on the study or studies that examined the relationship of interest (e.g., the longitudinal relationship between job performance and justice; Wu, Sturman \& Wang, 2013). In some instances, only one study provided information on the relationship of interest (e.g., the longitudinal relationship between justice and LMX; Wilson, 2011). Note that, when possible, we used dyadic tenure, which measured the duration of the relationship between a supervisor and a subordinate, as it is suggested that dyadic duration should be considered when the effects of time in LMX research are examined with temporal variables (Mossholder et al., 1990). For determining relationships with overall justice, we used estimates based on all justice-related items when available (i.e., Hausknecht et al., 2011; Wilson, 2011; Wu et al., 2013); otherwise, we averaged relationships reported for each of the various dimensions of justice (i.e., Cohen-Charash \& Spector, 2001). In short, we attempted to build upon the existing literature to provide as accurate point-estimates as possible for our use in the simulations. Studies used to gather our cross-sectional relationship are described in the top of Table 1.

We employed the same approach for considering longitudinal relationships. In addition to needing to obtain specific effect sizes, however, we needed to ensure that the effect sizes reflected the same time-gap. Thus, for any effect size obtained, we had to convert the relationship to represent the same longitudinal gap, which we set to be $1 / 3$ year (the logic for the specific time frame is explained in the subsequent section).

In some instances, no conversion was needed (e.g., Wu et al., 2013). In others, the time gaps were longer (e.g., 6 months or 7 months). To convert these values to provide a 4-month 
estimate, we took the $\mathrm{N}^{\text {th }}$ root of the correlation, where $\mathrm{N}$ was equal to the time span (in months) of the study, and then raised it to the $\mathrm{M}^{\text {th }}$ power, where $\mathrm{M}$ represented four months. Because we are considering these correlations in a longitudinal context,

$$
\rho_{\mathrm{t} t+\mathrm{k}}=\rho_{\mathrm{t} t+\mathrm{m}} \rho_{\mathrm{t}+\mathrm{m} t+\mathrm{k}}
$$

where $0<\mathrm{m}<\mathrm{k}$ (Kenny \& Campbell, 1989). Expressed in writing, the correlation between a measure at month one and month three is equal to the correlation between the measures at month 1 and month 2 times the correlation between the measures at month 2 and month 3 . Because we are assuming that, over the short-run, this relationship is stable, the correlation between a measure at month 1 and month $\mathrm{N}$ is equal to $\left(\rho_{\mathrm{t} t+1}\right)^{\mathrm{N}}$. Taking the $\mathrm{Nth}$ root of a correlation across two time periods thus provides an estimate of the correlation for a one-month time frame, and then raising that to the Mth power provides an estimate of the correlation between the measures at month 1 and month M. So, for example, if a study reported the correlation between two variables for a 7 month time span, we calculated $\left.\left(\mathrm{r}^{\wedge} 1 / 7\right)^{\wedge} 4\right)$. Given all time frames were within a few months of the 4-month target (values ranged from 4 months to 7 months), even if effects are non-linear, the differences in the estimate from this conversion should be negligible.

Information pertinent to obtaining the requisite longitudinal relationships is shown in the bottom of Table 1. For both cross-sectional and longitudinal relationships, we used corrected correlations from available meta-analyses, or when based on individual studies, corrected the observed correlations for unreliability reported in the original studies. The final correlation matrix used in the study is shown in Table 2.

\section{Data generation}

We wanted to represent a "reasonable" number of time periods, and capture both early and later stages of the LMX relationship. We used Google Scholar to search for studies that used the 
words "dyadic tenure" and "LMX." This search yielded 52 studies, of which 35 included information on a sample's mean dyadic tenure (with two reporting two samples), and 29 reporting the standard deviations of those estimates (again, with two studies reporting for two samples). The studies and dyadic tenure summary statistics are provided in Appendix A. The average dyadic tenure, weighted by sample size, was 3.02 years $(S D=3.33)$. These values indicate that $90 \%$ of LMX relationships are 7.29 years or shorter. We thus sought to simulate data over this time span to represent a realistic range of values; however, we also performed supplemental analyses at the $75^{\text {th }}$ percentile (5.27 years) and at the mean (3.02 years). This will fully capture the range of dyadic tenures that are likely to be observed in potential organizations. Furthermore, since longitudinal studies of LMX typically capture LMX at intervals of weeks or months (e.g., Bauer \& Green, 1996; Nahrgang et al., 2009; Wilson, 2011), we simulated three data points per year (equivalent to observations every 4 months).

Data for the study were generated using a multi-step process (mathematical details provided in Appendix B). First, tenure was created and set to 0 years. However, we needed all data expressed in standardized units. Based on the aforementioned review of dyadic tenure levels (mean of 3.02 and SD of 3.33), in standardized units, 0 years of dyadic tenure is -0.907 standardized units. Additionally, a four-month increase in dyadic tenure is equal to an increase of 0.1001 standardized units. Second, we simulated performance, justice, and LMX (in that order) to conform to the desired correlation matrix (from Table 2). Mathematical details for this process are provided in Appendix B. Put briefly, based on the correlation matrix, we compute the regression coefficients appropriate for predicting each next variable. Thus, for generating performance, it is based on the correlation between tenure and performance; for predicting justice, it is based on the correlations of tenure, performance, and justice; and for predicting LMX, it is based on the 
correlations of tenure, performance, justice, and LMX. We also compute the R-square for each analysis (cf., Greene, 1993). Because all the coefficients are standardized, we compute and employ standardized regression coefficients. For each simulated person, we compute the expected value of the variable based on the regression coefficients and the already-generated variables. We then add random noise to the variable in proportion to the amount of variance not explained by the coefficients (i.e., $1-\mathrm{R}^{2}$ ). At this point, the cross-sectional data for the initial time period was generated.

Third, we then needed to "age" the data. This was accomplished by first increasing tenure by four months (in standardized units). Note that, because of the way tenure "ages" with time, we could not use an approach like structural equation modeling and thus relied on simulation to generate individual-level data rather than simulations of covariate or correlational matrices. Then, the values for performance, justice, and LMX were created to conform to the entire correlation matrix as described above (and as in Appendix B). That is, each variable was created so that it had the specified longitudinal correlations with data from the prior time period (step 2), but also crosssectionally with the data created in this step. The third step was then repeated 20 more times, so that we had data for 22 observations per simulated person, representing a span of $7 \frac{1}{3}$ years. We performed the simulation for a sample of 1000 hypothetical employees. A sample size of 1000 is sufficient for reporting results to the norm of two decimal places (Bedeian, Sturman, \& Streiner, 2009), and yet does not yield so large a sample as to make analyses unwieldy or make significance testing meaningless.

An Excel program is available from the authors upon request that implements the simulation methodology used in this paper. Seeing the actual program may facilitate interpretation of the mathematics reported in Appendix B. Those interested may also be able to adapt the system 
to potentially address other research questions.

\section{Simulation Validation}

As our intent is to use the simulation to draw inferences intended to help advance LMX theory, it is important to present evidence that provides some confidence in the conclusions that are drawn (Kleindorfer, O’Neill, \& Ganeshan, 1998; Naylor \& Finger, 1967; Sargent, 2013; Van Horn, 1971). Unfortunately, much of what makes simulation a desirable methodology for certain types of problems (complex systems where actual data on the entire system is difficult or impossible to get) makes it challenging to validate (Van Horn, 1971). Ideally, we would validate our system again objective, real-world models of the same system (Naylor \& Finger, 1967), but as noted earlier, there are significant challenges to obtaining large and longitudinal datasets of LMX.

The process of simulation validation is not about proving the "truth" of a model; rather, it is about providing some confidence in the inferences drawn from the simulation, which then later may be subject to empirical testing (Van Horn, 1971). We employ the classic three-stage validation process model originally proposed by Naylor and Finger (1967). Based on a combination of philosophy of science methods - rationalism, empiricism, and positive economics - the authors proposed that validation consists of (1) developing the simulation model based on theory and available evidence, (2) empirically testing the model's assumptions, and (3) comparing the input-output relationships of the model to real systems (Naylor \& Finger, 1967; Sargent, 2013; Van Horn, 1971).

The first stage is not one tested empirically, but rather an assessment (by the researcher(s), system user, or members of the external scientific community) that the model is driven by prior theory and evidence (Schrank \& Holt, 1971). For this purpose, we provide the methodological details of how the simulation was built, as well as re-emphasize that the simulation parameters are 
based on existing correlations among the focal variables. The validation of the simulation in the second stages is an empirical process. This involves testing the underlying assumptions of the model and the inferences drawn from the simulation. Validation in the third stage is essentially our process of hypothesis testing (Sargent, 2013), and ultimately an issue for future research to establish if the simulation's findings are upheld by future empirical research if/when data become available to directly test these predictions (Van Horn, 1971). Ideally, validation of simulations provides verification akin to a Turing Test (Turing, 1963), in that we are looking to see if the results of the simulation are indistinguishable from the results of real people (Sturman \& Milkovich, 1995). For our purposes here, we begin this process by testing if the results of the simulation are comparable to prediction based on appropriate theory. Ultimately, "the final decision concerning the validity [of a simulation] must be based on its predictions" (p. B97, Naylor \& Finger, 1967).

Validation of Simulation Assumptions. The simulation's assumptions are described in our methodological description of the system. Aspects of these assumptions accuracy and appropriateness can be tested empirically.

As with the combination of meta-analysis and SEM, a potential risk of combining correlations from diverse and non-overlapping studies is that study-specific characteristics may affect the observed correlations, and the resultant combined matrix may be invalid (Viswesvaran \& Ones, 1995). We thus first explicitly tested if the matrix used in the simulation was positive definite. Using Mathematica (Wolfram Research, 2011), we tested and confirmed that each of the matrices used in the simulation were positive definite.

The next step of validating our assumptions was to verify the computer model. That entails verifying that the computer code itself is generating data as intended (Sargent, 2013). 
Using the dataset, we computed the correlation matrices for all cross-sectional relationships and all relationships with a 4-month time lag. Note that for the purposes of the validation, we did not assess correlations with tenure because values did not vary within each time period (i.e., they all began at the unstandardized value of 0 for all simulated individuals, and increased at the same rate). Altogether, there were 255 separate correlations across the 22-time period sample. This comes from 3 cross-sectional correlations from each of the 22 time periods (so, 3 x $22=66$ crosssectional correlations) and 9 longitudinal correlations from each of the 21 one-time-period lags (so, 9 x 21 = 189) (see Table 2). We then subtracted the observed correlation from the expected correlation. The mean error was $-0.020(\mathrm{SD}=0.028)$. Furthermore, no absolute deviation was greater than .12. Additionally, we computed the $95 \%$ confidence interval for each of the 255 correlations, and fewer than 5\% (3.9\%) did not contain the specified true score. Thus, we were confident that the computer simulation was generating the data as desired.

\section{Analytical Approach to Hypothesis Tests}

To test hypotheses 1-4, we employed hierarchical linear modeling (HLM). Using the entire dataset, we created three models to predict the three key outcomes variables: LMX, job performance, and justice. Each dependent variable was modeled at time t. For each model, we tested if the dependent variables - tenure, tenure-squared, lagged values of the other two key variables (i.e., from t-1), and the interactions of tenure and the lagged key variables—-predicted the focal outcome. The intercept term was modeled as a random effect to account for variance across individuals in their starting levels (and more generally because multiple observations were nested within individuals).

To test hypotheses 5 and 6, we conducted an HLM analysis with LMX (from time t) as the dependent variable. The independent variables were the lagged level of justice (t-1), the lagged 
level of performance (t-1), the change in justice (from $t-2$ to $t-1$ ), and the change in job performance (from t-2 to t-1). Given our 22 time periods, and each regression includes data from 3 periods ( $\mathrm{t}-2$, $\mathrm{t}-1$, and $\mathrm{t}$ ), this yielding 20 cases per individual. Because of the lack of independence across cases (multiple observations are nested within the individual), the model's intercept was modeled as a random effect.

\section{RESULTS}

\section{Hypothesis Tests}

Moderating Effects of Tenure. Our hypothesis tests supported most, although not all, of our predictions. The first four hypotheses predicted moderating effects for tenure. These results are reported in Table 3. For predicting LMX, tenure, job performance, and justice all had positive relationships with LMX. The positive effects for justice, though, decreased as tenure increased ( $p$ $<.001)$, although the effect for job performance did not $(\mathrm{p}=.522)$. This supports Hypotheses 1 , although fails to support Hypothesis 2. While justice and performance affect LMX, the effect of justice appears to be stronger for newcomers than for employees in more mature stages of their LMX relationship.

Hypotheses 3 and 4 predicted that the effect of LMX on justice and job performance would be positively moderated by tenure. For predicting both job performance and justice, the main effects of LMX were positive (both at $\mathrm{p}<.001$ ) and the effects of LMX on both justice and performance become stronger as tenure increases (at $\mathrm{p}<.01$ for job performance and $\mathrm{p}<.001$ for justice), thus supporting our hypotheses. Although not specifically hypothesized, it is also worth noting that the effect of justice on future job performance decreased with tenure $(\mathrm{p}<.001)$, but the effect of job performance on future justice increased with tenure $(\mathrm{p}<.001)$.

Effects of Changes in Justice, Performance, and LMX. The next two hypotheses 
examined how changes in job performance and justice influenced LMX. Results are presented in Table 4 and support the hypotheses. The effect of justice at $\mathrm{t}-1$ for predicting LMX at $\mathrm{t}$ was not significant $(\mathrm{p}=.613)$; yet, changes in justice perceptions had a strong effect $(\mathrm{B}=0.42, \mathrm{p}<.001)$,

supporting Hypothesis 5. This suggests that for understanding the effects of justice perceptions, it is not so much one's most recent perceptions of justice, but rather how much these perceptions have changed that influence later levels of LMX.

The effect of job performance, though, was very different. Performance from t-1 had a strong positive effect on LMX $(B=0.31 ; p<.001)$, but the effect of performance changes was negative (average $\mathrm{B}=-0.20 ; \mathrm{p}<.001$ ). This indicates that while high performance is associated with higher LMX, the effect is stronger when performance is more stable than when it is more dynamic. This supports Hypothesis 6.

\section{Supplemental Analyses and Robustness Checks}

The nature of our simulation methodology required a number of assumptions. While providing sufficient detail about the methodology itself is one way to help bolster confidence in our approach, another approach is to run additional analyses with different sets of assumptions to see if our findings remain consistent with different sets of inputs. Thus, we ran a series of supplemental analyses to test the robustness of our findings. All of these analyses are available upon request.

Our supplemental analyses involved four sets of tests, with each set involving five replications. First, we created five additional datasets using the same parameters as specified in the methods section (i.e., pure replication). Second, we created five datasets but with 16 time periods rather than 22 (i.e., the $75^{\text {th }}$ percentile of the distribution of tenure). Third, we created five datasets with 9 time periods (i.e., the median from the distribution of tenure). Fourth and finally, 
we ran a set of five simulations with a weaker correlation matrix. Thus, in total, we analyzed an additional 20 additional datasets.

For the fourth set of analyses, we created a correlation matrix based on the lower bound of the $95 \%$ confidence interval of each correlation, as reported in Table 1 . When we tried to run this analysis, however, the resultant matrix was not positive definite. We determined that the lack of positive definite status was largely attributable to the correlation between justice at T1 and T2 (which was 0.78 ). We lowered this correlation slightly (to 0.76 ), which made the matrix positive definite and thus made the rest of the simulation process viable.

Each of the supplemental datasets were analyzed using the same methods as described in the paper. Thus, in all, each hypothesis was tested 20 more time. The majority of analyses replicated our findings reported above.

We found consistent support for hypotheses 1, 3, 5, and 6 in all 20 supplemental analyses. Note that, similar to above, hypothesis 2 was largely not supported (it was supported in one analysis involving the 16 time-period simulation, but was not supported in any of the other 19 simulations). Hypothesis 4, however, received mixed support. While the hypothesized positive interaction between LMX and tenure for the prediction of performance was supported in the above analyses, it was supported in 3 of the 5 replications (with 22 time periods). It was only supported in 2 of the 16 time-period replications, 1 of the 9 time-period replications, and none of the replications based on the weaker correlations.

Overall, the replications and sensitivity analyses suggest that the support for hypotheses 1 , 3,5 , and 6 is strong and not a result of spurious findings or random error. The failure to support hypothesis 2 is also consistent. While we supported hypothesis 4 , the additional analyses suggest that this finding should be interpreted with some caution, as it does not consistently replicate in 
different simulations.

\section{DISCUSSION}

The philosopher Michael Polanyi is purported to have quipped, "We know more than we know we know." This paper shows that, for research on LMX, this is indeed true. While empirical limitations have hindered long-term, repeated measure data collection of LMX, existing findings can be used to extrapolate (essentially, deduce) what sort of long-term effects might exist. The simulation employed in this paper created data that is purely based on relationships reported in other research. Nonetheless, although based on no more than these prior correlational findings, we have deduced the presence of non-linearities, interactions, and various dynamic effects. Our results provide important implications for both LMX theory and future empirical research.

\section{Contributions to LMX Theory}

This study was able to look at how relationships of LMX with two particular key variables - job performance and justice — change with time. As a result, a number of specific key findings emerged.

First, this paper indicates that relationships with LMX differ for relative new hires versus those in more "mature" stages of development. While prior research showing that a positive relationship between tenure and LMX has already suggested that those in more mature stages will have higher LMX, our findings here indicate that the antecedents and consequences of LMX specifically differ in later stages. Previous longitudinal research showed that LMX continues to develop as the variables that affect LMX interact and accumulate over time (Gerstner \& Day, 1997; Nahrgang et al., 2009). Our results suggest that both justice and performance relate to LMX, but the effects of justice are weaker in these more mature stages. Alternatively, the effects of LMX on performance and justice become stronger as the LMX relationship progresses. 
Second, we have demonstrated that time plays an essential role for the conceptualization and understanding of LMX (Burton et al., 2008; Day, 2014; George \& Jones, 2000; Nahrgang et al., 2009; Shamir, 2011). This is exhibited in two ways. First, the relationship of antecedents and consequences of LMX are affected by the tenure of the LMX relationship. Second, our results also highlight the need to consider trends when predicting LMX. The importance of trends for predicting human resource outcomes is gaining attention (e.g., Chen et al., 2011; Hausknecht et al., 2011; Reb \& Cropanzano, 2007; Sturman \& Trevor, 2001), and our results suggest that, although previously unexplored, trends have a place in LMX research as well. Note that, overall (i.e., based on correlations), both positive levels and trends in performance and justice are positively related to LMX. Yet the effects become very different after controlling for the lagged level of performance and justice. That is, for someone who is currently a high-performer, if that high performance is a result of a recent increase in performance, then the positive effects associated with the high performance will be diminished. In contrast, considering someone with currently high levels of overall justice, if that justice was achieved by a marked short-term increase, the recent positive change has a more positive effect on LMX than would be expected from just the current high level of justice. In other words, an individual who experiences a sudden increase in justice perceptions (call it the result of a discrepant event, an event creating a gestalt characteristic, or an anchoring event) is predicted to have higher LMX than an individual whose justice perceptions rose to the same level only gradually. The results imply that changes in justice perceptions are very salient, and an important consideration for understanding LMX development.

It is worth reiterating that these results are empirical implications deduced from the existing literature detailing relationships of LMX with performance, justice, and tenure. Trend information was not a specific parameter in the simulation, nor did we explicitly model any sort 
of non-linear relationship or interaction. Although certainly one could take issue with the findings of a specific study or meta-analysis that informed our correlation matrices, and certainly LMX research would benefit from more empirical work on less-studied relationships (e.g., in particular, the relationships between LMX, justice, and performance at different time periods), these results are the direct mathematical implications of the various (linear) relationships that have been reported previously in academic literature. Furthermore, even when we base the simulation on somewhat weaker relationships, the same general pattern of results is found, suggesting that the findings may indeed be robust across different circumstances.

\section{Methodological Contributions}

While the focus of this paper is on LMX theory, the nature of the methodology and its potential for other research does merit some particular attention. While calls have been made to employ the simulation methodology more often in organizational science, and in particular for theory development (Davis et al., 2007; Harrison et al., 2007; Weinhardt \& Vancouver, 2012), it is rarely employed (some notable exceptions: Nystrom, 1973; Vancouver et al., 2010). This paper provides a demonstration of one way in which simulation can be used to test theory. The process by which the present simulation builds off existing empirical studies and generates a dataset that therefore conforms to current findings should provide some greater confidence in conclusions drawn from the simulated data. The approach we employed in this study can be used elsewhere. Its requirements are simply (a) the variables being examined must have been studied, at least in terms of their relationships with the other variables in the study, (b) the variables must have been examined longitudinally with empirical results describing the covariation between the variables in the study at two time periods, and (c) some sort of temporal variable needs to be examined (e.g., age, job experience, organizational tenure). Other domains that lament the lack of long-term 
longitudinal studies or within-person investigations may indeed benefit by taking a similar approach. We hope that part of our contribution is that this paper will serve as a model for other researchers to use simulation as a methodological tool for theory development in other areas.

\section{Practical Implications}

In addition to the theoretical implications, our findings have important implications for practice. Given our findings are indeed deduced from prior empirical findings, the analyses from this paper suggest practical courses of action that could improve managerial practice.

Most clearly, our results demonstrate the importance of early interactions between a leader and a subordinate. In particular, subordinates' perceptions of justice early in a dyad's tenure are critical for affecting both future LMX and future performance. The effects of justice perceptions are strongest at low levels of tenure, and at the same time, changes in justice perceptions appear to be highly salient. Thus, the initial level and early changes to justice perceptions seem to be critical for the development of LMX. Conversely, extrapolating from these results, it appears that after roughly three years of dyadic tenure (roughly the mean level of dyadic tenure in our review of 35 studies), justice plays a very limited role in further influencing LMX or job performance. While research on the dynamic nature of justice perceptions is still relatively new (Hausknecht et al., 2011), these findings specifically highlight the criticality of understanding and managing justice perceptions early in a dyadic relationship.

This study's results also reinforce the importance of effects associated with performance variability. While some prior work has shown that performance variability can influence overall evaluations of performance (e.g., Reb \& Cropanzano, 1997), our results suggest that performance variability influences LMX perceptions, which then have effects on both subordinates' justice perceptions and future performance ratings. Given that LMX perceptions seem to play a larger 
role in the prediction of performance as dyadic tenure increases, the implications of performance variability would seem to increase with time as well. The way performance cues are used may thus also be influenced by the extent to which the leader-member relationship has developed.

As a whole, our results more broadly indicate that managerial practice should consider the extent to which an LMX relationship has developed to inform how employee performance and justice perceptions can be improved. Time is clearly a complex contingency for managerial practice, and it creates a web of complexities even when considering such highly-studied and important constructs like job performance, justice perceptions, and LMX. Considering the contingency of time is a very practical matter for research to consider so that the implications of empirical findings can better inform managerial practice.

\section{Limitations}

Of course, as with all studies, this paper has limitations that moderate its potential implications. Most notably, this study uses a simulation. We use the simulation methodology because it is appropriate for our research question and because it overcomes the difficulties of other empirical research methodologies in this domain. As with any methodological approach, it has strengths and weaknesses (Davis et al., 2007; Harrison et al., 2007; McGrath, 1982).

Particular to our study, the method of data generation was determined by a very limited number of studies for some key relationships. Errors in these point estimates could have notable changes in subsequent results. While error in point estimates can affect the interpretation of findings for any study, the dependence of simulation on these initial estimates makes it a more salient issue. We relied on the best point estimates we could find, and in particular employed more established findings, such as those from meta-analyses, when available. We also showed that our findings are consistent when weaker relationships were used as the basis for the simulation. Nonetheless, 
given the difficulties of studying LMX longitudinally, the results of the simulation provide at least initial implications for both theory and future research in terms of how LMX may be expected to operate over time.

Related to this, because our point estimates come from different studies, as with SEM on meta-analytic correlation matrices, there are concerns of combining meta-analyses of different populations into a single matrix for subsequent analyses (Furlow \& Beretvas, 2005). Differences in sample sizes (both number of studies and samples within studies) across the various quantitative reviews also create variability in the precision of the various point estimates (Cheung \& Chan, 2005; Viswesvaran \& Ones, 1995). While the consistency of our findings across the various replications and sensitivity analyses do somewhat mitigate these concerns, it nonetheless should be noted as an issue that is pertinent to this simulation approach as well as with the related combination of meta-analysis and SEM.

A third issue with the relationships we use to generate our data is that we are assuming that they capture the causal processes underlying LMX and related changes. Unlike other simulations (cf., Vancouver et al., 2010; Vancouver et al., 2010), we do not specifically model the processes that cause the change. Thus, there may be unmeasured constructs that play an important role in LMX changes over time. We essentially present evidence that the current body of correlational data yields results that are largely consistent with our predictions. Nonetheless, this also makes clear that more detail is needed on the causal processes that underlie how LMX changes over time, which may be best studied with a different simulation methodology, field data, or experiments.

It should also be noted that our simulation methodology assumes that the correlations between our variables of interest remain constant over time. This is largely a necessary 
assumption, as there is as yet little research about how the relationships we examine in this study might change with time. One notable exception (Sturman, 2003) shows that the relationship between tenure and performance changes as tenure increases. We again conducted supplemental analyses where we changed the performance-tenure relationship as tenure increased in line with the findings reported in Sturman (2003), and results remained consistent. Nonetheless, the assumption that relationships remain stable over time is an assumption that, for this research and for many other domains, merits further scrutiny.

Our study is also limited by the variables under consideration. We focus our examination of independent variables on simply tenure as a measure of time, job performance, and overall organizational justice. Previous research has shown all of these independent variables to be multidimensional. Justice in particular is frequently represented with four dimensions (i.e., distributive, procedural, informational, and interpersonal). Yet although there has been significant attention in exploring the four different dimensions of organizational justice, recent research has argued that overall justice perceptions are better able to capture changes in individuals' perception of farness, particularly when measuring relationships with other global outcome variables (Holtz \& Harold, 2009). Holtz and Harold also suggest that overall justice perceptions, which are defined as "global evaluations of the fairness of an entity based on personal experiences as well as on the experiences of others" (2009, p. 1185), allow for more precision when capturing "how employees experience fairness in the workplace" because "employees more naturally consider issues of justice in a holistic manner" $(2009$, p. 1186). Given that the purpose of this paper is to begin to consider how LMX operates over time, and in particular the novelty of this area empirically, it would be premature to focus on specific justice dimensions to investigate the dynamics between LMX, overall justice trends, and overall job performance in longitudinal waves. Examination of 
overall justice perceptions provides broader but clearer information in predicting interaction effects between subordinates' justice perception and LMX, as well as dynamic performance.

Certainly, greater complexity could yield potentially richer theory, and thus our contributions are limited by the scope of our construct set. That said, the results of our study provide deeper insight into how LMX could be expected to develop and change over time given what is currently known, and so can be used as a basis for future theoretical development.

\section{Future Research}

The present study sought to broaden our understanding of LMX as a dynamic construct by investigating the implications of what we currently know about how LMX might operationalize over a longer time frame. Certainly, it would be fruitful for future research to collect longitudinal subject-level data to test our conclusions. It would be particularly useful to examine the relationship between LMX at different time periods and validate our finding that relationships with justice and performance change with increased tenure. Future research, both empirical and theoretical, should also investigate further the effects of changes in LMX associated with key covariates. Yet uniting them all, it is clear that understanding LMX means understanding how the relationship between the supervisor and subordinate develops and changes with time. This development is inherently wrapped up with levels and changes in job performance and justice.

Our findings also present a valuable opportunity for falsification. Given our simulated data is the direct result of prior research, failure to replicate our findings indicates some sort of different mathematical relationship. If a study based on field data reports similar linear relationships (as we would expect, particularly for the results based on meta-analyses), but different regression model results, this would be an indication of more complex relationships: that is, interactions and non-linear relationships. Contrasting results based on actual employee data to 
the mathematically derived relationships in the simulation could present a means to detect nonlinear relationships and illustrate how the more refined understanding of the relationships among the variables has important empirical consequences. At the same time, studies using actual employee data also present opportunities for further validating the simulation (Kozlowski et al., 2013). Subsequent research findings that support the simulation's predictions help establish that the system's outputs have "the accuracy required for the model's intended purpose over the domain of the model's intended applicability" (p. 18, Sargent, 2013). Simulation should not be seen as a method in opposition to data collection; rather, simulation and human data can be reciprocal, following a process where the bounds of each methodology can be pushed and developed in an ongoing cyclic process of research developing, testing, and expanding on theoretical questions.

Of course, simulation is a relatively rare methodology in organizational sciences (particularly for theory development), and appropriate or not, our experience is that most researchers would be more comfortable drawing conclusions from empirical research based on an actual longitudinal sample of employees. It would certainly be valuable for future research to examine ours and additional hypotheses using extensive longitudinal data. Much of the motivation for our methodological approach stems from the true difficulty in obtaining this sort of data. Thus, while the call for more longitudinal research remains, it may be necessary to employ alternative methodologies like simulation when data are difficult to acquire. 


\section{ENDNOTES}

1. Estimates for the correlation between performance and tenure are computed from results reported in Sturman (2003), Table 2 (Set 3). Estimates assume that performance is a subjective measure (i.e., supervisor-rated; coded as 1 versus 0 for an objective measure), and task complexity was rated as 4 (the middle of the scale, which was from 1 to 7 ). Formula is as follows: $\mathrm{r}=\tan \mathrm{H}[(0.260-(0.034 *$ tenure $)+(0.135 * 1)-(0.023 * 4)-(0.003 * 1 *$ tenure $)+(0.008 * 4$ * tenure)]. Values were computed for the 22 time periods and then averaged. Correlations ranged from .26 to .29 , and had an average of .28. Given the range was relatively small, to facilitate interpretation and replication, the average value was used in the simulation. 


\section{REFERENCES}

Ansari, M. A., Aafaqi, R., \& Ahmad, Z. A. (2009). Perceived delegation and work outcomes: The moderating role of cultural orientations in the Malaysian business context. Academy of Management, Chicago.

Ansari, M. A., Bui, L. B., Utama, K. D., \& Aafaqi, R. (2007). Leader-member exchange and work outcomes: The mediating role of perceived delegation in the Malaysian business context. Academy of Management, Philadelphia.

Ariely, D., \& Carmon, Z. (2000). Gestalt characteristics of experiences: the defining features of summarized events. Journal of Behavioral Decision Making, 13, 191-201.

Ashford, S.J., \& Black, J.S. (1996). Proactivity during organizational entry : the role of desire for control, Journal of Applied Psychology, 81, 199-214.

Ballinger, G.A., \& Rockmann, K.W. (2010). Chutes versus ladders: anchoring events and a punctuated-equilibrium perspective on social exchange relationships. Academy of Management Review, 35, 373-391.

Bauer, T. N., \& Green, S.G. (1996). Development of leader-member exchange: a longitudinal test. Academy of Management Journal, 39, 1538-1567.

Beal, D. J., Weiss, H. M., Barros, E. \& MacDermid, S. M. (2005). An episodic process model of affective influences on performance. Journal of Applied Psychology, 90,1054-1086.

Bedeian, A. G., Sturman, M. C., \& Streiner, D. L. (2009). Decimal dust, significant digits, and the search for stars. Organizational Research Methods, 12, 687-694.

Blau, P. M. (1964). Exchange and power in social life. New York: Wiley.

Bluhm, D. J. (2012). Stable versus Shifting Ethical Leadership: The Impact on Follower Positivity and Performance (Doctoral dissertation). 
Burton, J.P., Sablynski, C.J., \& Sekiguchi, T. (2008). Linking justice, performance, and citizenship via leader-member exchange. Journal of Business and Psychology, 23, 51-61.

Chen, G., Ployhart, R. E., Cooper-Thomas, H., Anderson, N., \& Bliese, P. D. (2011). The power of momentum: A new model of dynamic relationships between job satisfaction change and turnover intentions. Academy of Management Journal, 54,159-181.

Cheng, J. W., Lu, K. M., Chang, Y. Y., \& Johnstone, S. (2013). Voice behavior and work engagement: the moderating role of supervisor-attributed motives. Asia Pacific Journal of Human Resources, 51, 81-102.

Cheung, M. W. L., \& Chan, W. (2005). Meta-analytic structural equation modeling: a two-stage approach. Psychological Methods, 10, 40-64.

Cohen-Charash, Y., \& Spector, P.E. (2001). The role of justice in organizations: a meta-analysis. Organizational Behavior and Human Decision Processes, 86, 278-321.

Colquitt, J.A., Conlon, D.E., Wesson, M.J., Porter, C.O.L.H., \& Ng, K.Y. (2001). Justice at the Millennium: A meta-analytic review of 25 years of organizational justice research. Journal of Applied Psychology, 86, 425-445.

Dansereau, F., Graen, G., \& Haga, W.J. (1975). A vertical dyad linkage approach to leadership within formal organizations: a longitudinal investigation of the role making process. Organizational Behavior and Human Performance, 13, 46-78.

Davis, J. P., Eisenhardt, K. M., \& Bingham, C.B. (2007). Developing theory through simulation methods. Academy of Management Review, 32, 480-499.

Day, D. V. (2014). The future of leadership: Challenges and prospects. In D. B. Day (Ed.), The Oxford Handbook of leadership and Organizations. Oxford University Press: New York. Day, D.V., Sin, H., \& Chen, T.T. (2004). Assessing the burdens of leadership: effects of formal 
leadership roles on individual performance over time. Personnel Psychology, 57, 573-605.

de Wit, F. R., Greer, L. L., \& Jehn, K. A. (2012). The paradox of intragroup conflict: A metaanalysis. Journal of Applied Psychology, 97, 360-390.

Deadrick, D.L., Bennett, N., \& Russell, C.J. (1997). Using hierarchical linear modeling to examine dynamic performance criteria over time, Journal of Management, 23, 745-757.

Dienesch, R. M., \& Liden, R.C. (1986). Leader-member exchange model of leadership: a critique and further development. Academy of Management Review, 11, 618-634.

Dijksterhuis, A., \& Bargh, J. A. (2001). The perception-behavior expressway: automatic effects of social perception on social behavior, In M.P. Zanna (Eds.), Advances in Experimental Social Psychology: 1-40. San Diego, CA: Academic Press.

Duarte, N. T., Goodson, J. R., \& Klich, N. R. (1994). Effects of dyadic quality and duration on performance appraisal. Academy of Management Journal, 37, 499-521.

Dudley, N. M., Orvis, K.A., Lebiecki, J.E., \& Cortina, J. M. (2006). Meta-analytic investigation of conscientiousness in the prediction of job performance. Examining the intercorrelations and the incremental validity of narrow traits. Journal of Applied Psychology, 91, 40-57.

Dulebohn, J. H., Bommer, W. H., Liden, R. C., Brouer, R. L., \& Ferris, G. R. (2012). A metaanalysis of antecedents and consequences of leader-member exchange: integrating the past with an eye toward the future. Journal of Management, 38, 1715-1759.

Eisenberger, R., Shoss, M. K., Karagonlar, G., Gonzalez-Morales, M. G., Wickham, R. E., \& Buffardi, L. C. (2013). The supervisor POS-LMX-subordinate POS chain: Moderation by reciprocation wariness and supervisor's organizational embodiment. Journal of Organizational Behavior. Online first. DOI: 10.1002/job.1877

Engle, E. M., \& Lord, R. G. (1997). Implicit theories, self-schemas, and leader-member 
exchange. Academy of Management Journal, 40, 988-1010.

Erdogan, B., Kraimer, M. L., \& Liden, R. C. (2004). Work value congruence and intrinsic career success: The compensatory roles of leader-member exchange and perceived organizational support. Personnel Psychology, 57, 305-332.

Erdogan, B., Liden, R. C., \& Kraimer, M. L. (2006). Justice and leader-member exchange: the moderating role of organizational culture. Academy of Management Journal, 49, 395-406.

Feldman, D.C., \& Brett, J.M. (1983). Coping with new jobs: A comparative study of new hires and job changers. Academy of Management Journal, 26, 258-272.

Finch, D. M., Edwards, B. D., \& Wallace, J. C. (2009). Multiple hurdle selection strategies: Simulating the effects on adverse impact and predictive efficiency for various predictor combinations. Journal of Applied Psychology, 94: 318-340.

Furlow, C. F., \& Beretvas, S. N. (2005). Meta-analytic methods of pooling correlation matrices for structural equation modeling under different patterns of missing data. Psychological Methods, 10, 227-254.

George, J. M., \& Jones, G. R. (2000). The role of time in theory and theory building. Journal of Management, 26, 657-684.

Gerstner, C. R., \& Day, D. V. (1997). Meta-analytic review of leader-member exchange theory: correlates and construct issues. Journal of Applied Psychology, 82, 827-844.

Gleick, J. (1987). Chaos: Making a New Science. Penguin Books: New York.

Gooty, J., \& Yammarino, F. J. (2011). Dyads in organizational research: conceptual issues and multilevel analyses. Organizational Research Methods, 14, 456-483.

Graen, G. B., \& Scandura, T. A. (1987). Toward a psychology of dyadic organizing. In L.L. Cummings \& B. M. Staw (Eds.), Research in Organizational Behavior: 175-208. 
Greenwich, CT: JAI Press.

Graen, G. B., \& Uhl-Bien, M. (1995). Relationship-based approach to leadership: Development of leader-member exchange (LMX) theory of leadership over 25 years: Applying a multilevel perspective. Leadership Quarterly, 6, 219-247.

Greene, W. H. (1993). Econometric Analysis (2 ${ }^{\text {nd }}$ edition). Macmillan Publishing Company: New York.

Greenberg, J. (1996). The quest for justice on the job. Thousand Oaks, CA: SAGE.

Harris, K. J. (2004). An examination of multiple predictors and outcomes from different dimensions of LMX relationship quality (Doctoral dissertation).

Harrison, J.R., Lin, Z., Carroll, G. R., \& Carley, K. M. (2007). Simulation modeling in organizational and management research. Academy of Management Review, 32, 12291245.

Hausknecht, J.P., Sturman, M.C., \& Roberson, Q.M. (2011). Justice as a dynamic construct: effects of individual trajectories on distal work outcomes. Journal of Applied Psychology, $96,872-880$.

Holtz, B.C., \& Harold, C.M. (2009). Fair today, fair tomorrow? A longitudinal investigation of overall justice perceptions. Journal of Applied Psychology, 94, 1185-1199.

Hooper, D.T., \& Martin, R. (2008). Beyond personal Leader-Member Exchange (LMX) quality: the effects of perceived LMX variability on employee reactions. Leadership Quarterly, $19,20-30$.

Hu, J., \& Liden, R. C. (2013). Relative Leader-Member Exchange Within Team Contexts: How and When Social Comparison Impacts Individual Effectiveness. Personnel Psychology, $66,127-172$. 
Huang, X., Chan, S. C., Lam, W., \& Nan, X. (2010). The joint effect of leader-member exchange and emotional intelligence on burnout and work performance in call centers in China. International Journal of Human Resource Management, 21, 1124-1144.

Huang, X., \& Iun, J. (2006). The impact of subordinate-supervisor similarity in growth-need strength on work outcomes: the mediating role of perceived similarity. Journal of Organizational Behavior, 27, 1121-1148.

Hwa, A. M. C., Ansari, M. A., \& Jantan, M. (2005). Upward influence and career outcomes: the mediating role of leader-member exchange and organizational support. Academy of Management, Honolulu.

Ilies, R., Nahrgang, J.D., \& Morgeson, F.P. (2007). Leader-member exchange and citizenship behaviors: a meta-analysis. Journal of Applied Psychology, 92, 269-277.

Jiang, K., Liu, D., McKay, P. F., Lee, T. W., \& Mitchell, T. R. (2012). When and how is job embeddedness predictive of turnover? A meta-analytic investigation. Journal of Applied Psychology, 97, 1077-1096.

Kacmar, K.M., Witt, L.A., Zivnuska, S., \& Gully, S.M. (2003). The interactive effect of leadermember exchange and communication frequency on performance ratings. Journal of Applied Psychology, 88, 764-772.

Kenny, D.A., \& Campbell, D.T. (1989). On the measurement of stability in over-time data. Journal of Personality, 57, 445-481.

Klein, H. J., \& Snell, S. A. (1994). The impact of interview process and context on performance appraisal interview effectiveness. Journal of Managerial Issues, 6, 160-175.

Kleindorfer, G.B., O’Neill, L., \& Ganeshan, R. (1998). Validation in Simulation: various positions in the philosophy of science. Management Science, 44, 1087-1099. 
Kozlowski, S. W. J., Chao, G. T., Grand, J. A., Braun, M. T., \& Kuljanin, G. (2013). Advancing multilevel research design: Capturing the dynamics of emergence. Organizational Research Methods, 16, 581-615.

Krasikova, D.V., \& LeBreton, J.M. (2012). Just the two of us: misalignment of theory and methods in examining dyadic phenomena. Journal of Applied Psychology, 97, 739-757.

Kunze, M., \& Phillips, J. (2011). The Influence of Employee Affect on Leader-Member Exchange and Perceptions of Psychological Contract Violation. International Journal of Management and Marketing Research, 4, 1-23.

Lam, K. Y. W. (2006). Make my boss happy: perceived work performance, supervisor-attributed motives, feedback-seeking behavior, leader-member exchange, and objective work performance (Dissertation).

Landry, G., \& Vandenberghe, C. (2009). Role of commitment to the supervisor, leader-member exchange, and supervisor-based self-esteem in employee-supervisor conflicts. The Journal of Social Psychology, 149, 5-28.

Liao, Y. (2013). A resource view and a social exchange view on leader-member dynamics: A meta-analysis of LMX and a study of supervisor monitoring influencing subordinate innovation. (Doctoral dissertation). Retrieved from hub.hku.hk/handle/10722/183049.

Liden, R. C., \& Graen, G. (1980). Generalizability of the vertical dyad linkage model of leadership. Academy of Management Journal, 23, 451-465.

Liden, R.C., Wayne, S.J., \& Stilwell, D. (1993). A longitudinal study on the early development of leader-member exchanges. Journal of Applied Psychology, 78, 662-674.

Lilly, J. D., Virick, M., \& Hadani, M. (2010). The dynamic nature of justice: influential effects of time and work outcomes on long-term perceptions of Justice. Social Justice Research, 23, 
$37-59$.

Loi, R., Yang, J., \& Diefendorff, J. M. (2009). Four-factor justice and daily job satisfaction: A multi-level investigation. Journal of Applied Psychology, 94, 770-781.

Martinko, M. J., Moss, S. E., Douglas, S. C., \& Borkowski, N. (2007). Anticipating the inevitable: When leader and member attribution styles clash. Organizational Behavior and Human Decision Processes, 104, 158-174.

Maslyn, J. M., \& Uhl-Bien, M. (2001). Leader-member exchange and its dimensions: Effects of self-effort and other's effort on relationship quality. Journal of Applied Psychology, 86, $697-708$

Masterson, S.S., Lewis, K., Goldman, B.M., \& Taylor, M.S. (2000). Integrating justice and social exchange: the differing effects of fair procedures and treatment on work relationships. Academy of Management Journal, 43, 738-748.

McGrath, J. E. (1982). Dilemmatics: The study of research choices and dilemmas. In J. E. McGrath, J. Martin, \& R. A. Kulka (Eds.) Judgment Calls in Research: 69-102. Sage Publications: Beverly Hills, CA.

Meiners, E. B., \& Boster, F. J. (2012). Integrative Process in Manager-Employee Negotiations: Relational and Structural Factors. Journal of Applied Communication Research, 40, 208228.

Mitchell, T.R., \& James, T.R. (2001). Building better theory: time and the specification of when things happen. Academy of Management Review, 26, 530-547.

Moss, S. E., Sanchez, J. I., Brumbaugh, A. M., \& Borkowski, N. (2009). The Mediating Role of Feedback Avoidance Behavior in the LMX — Performance Relationship. Group \& Organization Management, 34, 645-664. 
Mossholder, K.W., Niebuhr, R.E., \& Norris, D.R. (1990). Effects of dyadic duration on the relationship between leader behavior perceptions and follower outcomes. Journal of Organizational Behavior, 11, 379-388.

Nahrgang, J.D., Morgeson, F. P., \& Ilies, R. (2009). The development of leader-member exchanges: exploring how personality and performance influence leader and member relationships over time. Organizational Behavior and Human Decision Processes, 108, 256-266.

Naylor, T.H., \& Finger, J.M. (1967). Verification of computer simulation models. Management Science, 14, B92-B101.

Nystrom, P. C. (1973). Equity theory and career pay: A computer simulation approach. Journal of Applied Psychology, 57, 125-131.

Pitariu, A.H., \& Ployhart, R.E. (2010). Explaining change: Theorizing and testing dynamic mediated longitudinal relationships. Journal of Management, 36, 405-429.

Ployhart, R.E., Holtz, B.C., \& Bliese, P.D. (2002). Longitudinal data analysis applications of random coefficient modeling to leadership research. Leadership Quarterly, 13, 455-486.

Reb, J., \& Cropanzano, R. (2007). Evaluating dynamic performance: the influence of salient gestalt characteristics on performance ratings. Journal of Applied Psychology, 92, 490499.

Reb, J., \& Greguras, G. J. (2010). Understanding performance ratings: dynamic performance, attributions, and rating purpose. Journal of Applied Psychology, 95, 213-220.

Richards, D. A., \& Hackett, R. D. (2012). Attachment and emotion regulation: Compensatory interactions and leader-member exchange. Leadership Quarterly, 23, 686-701.

Sargent, R. G. (2013). Verification and validation of simulation models. Journal of Simulation, 7, 
$12-24$.

Scandura, T. A. (1999). Rethinking leader-member exchange: An organizational justice perspective. Leadership Quarterly, 10, 25-40.

Scandura, T. A., \& Schriesheim, C. A. (1994). Leader-member exchange and supervisor career mentoring as complementary constructs in leadership research. Academy of management Journal, 37, 1588-1602.

Schrank, W.E., \& Holt, C.C. (1971). Critique of verification of computer simulation methods. Management Science, 14, B104-B106.

Sekiguchi, T., Burton, J. P., \& Sablynski, C. J. (2008). The role of job embeddedness on employee performance: the interactive effects with leader-member exchange and organization-based self-esteem. Personnel Psychology, 61, 761-792.

Shamir, B. (2011). Leadership takes time : some implications of (not) taking time seriously in leadership research. Leadership Quarterly, 22, 307-315.

Sin, H. P., Nahrgang, J. D., \& Morgeson, F. P. (2009). Understanding why they don't see eye-toeye: An examination of leader-member exchange (LMX) agreement. Journal of Applied Psychology, 94, 1048-1057

Sluss, D.M., \& Thompson, B.S. (2012). Socializing the newcomer : the mediating role of leadermember exchange. Organizational Behavior and Human Decision Processes, 119, 114125.

Sparrowe, R.T., \& Liden, R.C. (2005). Two routes to influence: integrating leader-member exchange and social network perspectives. Administrative Science Quarterly, 50, 505-535.

Sparrowe, R.T., Soetjipto, B.W., \& Kraimer, M.L. (2006). Do leader's influence tatics relate to members' helping behavior? It depends on the quality of the relationship. Academy of 
Management Journal, 49, 1194-1208.

Sturman, M. C., Cheramie, R. A., \& Cashen, L. H. (2005). The impact of job complexity and performance measurement on the temporal consistency, stability, and test-retest reliability of employee job performance ratings. Journal of Applied Psychology, 90, 269-283

Sturman, M. C., \& Trevor, C. O. (2001). The implications of linking the dynamic performance and turnover literatures. Journal of Applied Psychology, 86, 684-696.

Sturman, M. C., \& Milkovich, G. T. (1995). Validating expert systems: A demonstration using Personal Choice Expert—A flexible employee benefit system. Decision Sciences Journal, 26, 105-118.

Sturman, M.C. (2003). Searching for the inverted U-shaped relationship between time and performance: meta-analyses of the experience/performance, tenure/performance, and ageperformance relationships. Journal of Management, 29, 609-640.

Sturman, M.C. (2007). The past, present, and future of dynamic performance research. Research in Personnel and Human Resources Management, 26, 49-110.

Sue-Chan, C., Chen, Z., \& Lam, W. (2011). LMX, coaching attributions, and employee performance. Group \& Organization Management, 36, 466-498.

Sun, P. Y., \& Anderson, M. H. (2012). The Importance of Attributional Complexity for Transformational Leadership Studies. Journal of Management Studies, 49, 1001-1022.

Sun, L. Y., Zhang, Z., Qi, J., \& Chen, Z. X. (2012). Empowerment and creativity: A cross-level investigation. Leadership Quarterly, 23, 55-65.

Thatcher, S., \& Patel, P. C. (2011). Demographic faultlines: a meta-analysis of the literature. Journal of Applied Psychology, 96, 1119-1139.

Thomas, C. H., \& Lankau, M. J. (2009). Preventing burnout: The effects of LMX and mentoring 
on socialization, role stress, and burnout. Human Resource Management, 48, 417-432.

Tse, H. H. M., Lam, C. K., Lawrence, S. A., \& Huang, X. (2013, July 29). When My Supervisor Dislikes You More Than Me: The Effect of Dissimilarity in Leader-Member Exchange on Coworkers' Interpersonal Emotion and Perceived Help. Journal of Applied Psychology. Advance online publication. doi: 10.1037/a0033862.

Turing, A. M. (1963). Can a machine think? In E. A. Feigenbaum \& J. Fledman (Eds.), Computers and thought. New York: McGraw-Hill.

Uhl-Bien, M., \& Maslyn, J. M. (2003). Reciprocity in manager-subordinate relationships: Components, configurations, and outcomes. Journal of Management, 29, 511-532.

Vancouver, J. B., Tamanini, K. B., \& Yoder, R. J. (2010). Using dynamic computational models to reconnect theory and research: Socialization by the proactive newcomer example. Journal of Management, 36, 764-793.

Vancouver, J. B., Weinhardt, J. M., \& Schmidt, A. M. (2010). A formal, computational theory of multiple-goal pursuit: integrating goal-choice and goal-striving processes. Journal of Applied Psychology, 95, 985-1008.

Van Horn, R.L. (1971). Validation of simulation results, Management Science, 17, 247-258.

Viswesvaran, C., \& Ones, D. S. (1995). Theory Testing: Combining Psychometric Meta-analysis and Structural Equations Modeling. Personnel Psychology, 48, 865-885.

Wakabayashi, M., \& Graen, G. B. (1984). The Japanese career progress study: A 7-year followup. Journal of Applied Psychology, 69, 603-614.

Wakabayashi,M ., \& Graen, G. B. (1989). Human resource development of Japanese managers: Leadership and career investment. Research in Personnel and Human Resources Management, 1, 235-256. 
Wakabayashi, M., Graen, G., Graen, M., \& Graen, M. (1988). Japanese management progress: mobility into middle management. Journal of Applied Psychology, 73, 217-227.

Wallis, N. C., Yammarino, F. J., \& Feyerherm, A. (2011). Individualized leadership: A qualitative study of senior executive leaders. Leadership Quarterly, 22, 182-206.

Wang, H., Sui, Y., Luthans, F., Wang, D., \& Wu, Y. (2012). Impact of authentic leadership on performance: Role of followers' positive psychological capital and relational processes. Journal of Organizational Behavior. Advance online publication. doi: 10.1002/job.1850.

Wayne, S. J., Shore, L. M., Bommer, W. H., \& Tetrick, L.E. (2002). The role of fair treatment and rewards in perceptions of organizational support and leader-member exchange. Journal of Applied Psychology, 87, 590-598.

Weinhardt, J.M., \& Vancouver, J.B. (2012). Computational models and organizational psychology: opportunities abound. Organizational Psychology Review, 2, 267-292.

White, C. D., Campbell, K. S., \& Kacmar, K. M. (2012). Development and Validation of a Measure of Leader Rapport Management: The LRM Scale. Institute of Behavioral and Applied Management.

Wilson, K.S., Sin, H.P., \& Conlon, D.E. (2010). What about the leader in leader-member exchange ? The impact of resource exchanges and substitutability on the leader. Academy of Management Review, 35, 358-372.

Wilson, R. (2011). Fairness in feedback: Effects of justice in performance appraisal. Unpublished doctoral dissertation, University of Houston. Retrieved from ProQuest Dissertations and Theses Database.

Wolfram Research (2011). Mathematica (version 8). Wolfram Research: Champaign, IL. Wu, X., Sturman, M. C., \& Wang, C. (2013). The motivational effects of pay fairness: A 
longitudinal study in Chinese star-level hotels. Cornell Hospitality Quarterly, 54, 185198.

Zhang, Z., Wang, M., \& Shi, J. (2012). Leader-follower congruence in proactive personality and work outcomes: The mediating role of leader-member exchange. Academy of Management Journal, 55, 111-130. 
TABLE 1

Cross-Sectional and Longitudinal Relationships

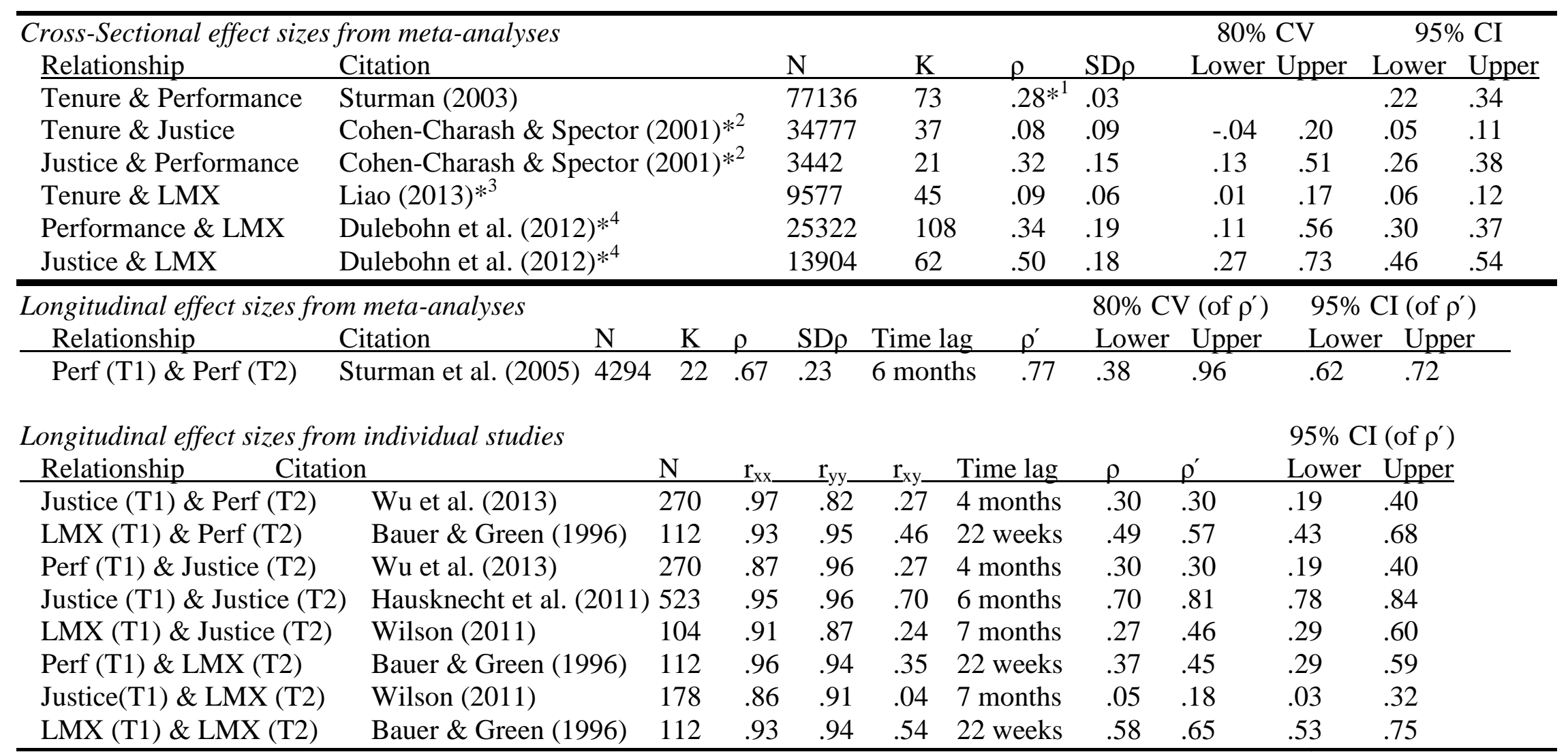

Notes: ${ }^{* 1}$ The estimated true relationship between tenure and performance is a function, as specified by Sturman (2003) Table 2 Set $3 . *^{2}$.We used the average correlation over the range of tenure values as the average correlation between tenure and performance for this study. The relationships with Justice in CohenCharash \& Spector (2001) are based on the average (weighted by total sample size) of the meta-analyses with distributive justice, procedural justice, and interactional justice. ${ }^{*}$ In Liao (2013), we used the correlation between Dyadic Tenure and LMX. ${ }^{*}$ The relationships with Justice in Dulebohn et al. (2012) are based on the average (weighted by total sample size) of the meta-analyses with distributive justice and procedural justice. $\mathrm{N}$ is sample size; $\mathrm{K}$ is the number of coefficients the meta-analysis is based on; $r_{\mathrm{xx}}$ is the reliability of the first variable in the relationship; $\mathrm{r}_{\mathrm{yy}}$ is the reliability of the second variable; $\mathrm{r}_{\mathrm{xy}}$ is the uncorrected correlation between two variables; $\rho$ is the meta-analytically derived estimated true relationship between the variables, corrected for unreliability, $\rho^{\prime}$ signifies the estimated true relationship at a consistent time lag of 4 months. The column Time lag reports the time between the measurement of variable 1 and 2 , as reported in the original study. 
TABLE 2

Simulation Correlation Matrix

\begin{tabular}{lllll|llll} 
& 1 & 2 & 3 & 4 & 5 & 6 & 7 & 8 \\
\hline 1. Tenure (T1) & 1 & & & & & & \\
2. Job Performance (T1) & .28 & 1 & & & & & & \\
3. Justice (T1) & .08 & .32 & 1 & & & & & \\
4. LMX (T1) & .09 & .34 & .50 & 1 & & & \\
\hline 5. Tenure (T2) & 1 & .28 & .08 & .09 & 1 & & & \\
6. Job Performance (T2) & .28 & .77 & .30 & .57 & .28 & 1 & & \\
7. Justice (T2) & .08 & .30 & .81 & .46 & .08 & .32 & 1 \\
8. LMX (T2) & .09 & .45 & .18 & .65 & .09 & .34 & .50 & 1 \\
& & & & & & & & \\
\hline
\end{tabular}


TABLE 3

Moderating Effects of Tenure

\begin{tabular}{|c|c|c|c|}
\hline & \multicolumn{3}{|c|}{ Dependent Variables (at Time T) } \\
\hline Variable (at time T-1) & Predicting LMX & $\begin{array}{c}\text { Predicting Job } \\
\text { Performance }\end{array}$ & Predicting Justice \\
\hline Intercept & $\begin{array}{c}-0.080 \\
(0.017)^{* * *}\end{array}$ & $\begin{array}{c}-0.096 \\
(0.021)^{* *}\end{array}$ & $\begin{array}{c}-0.046 \\
(0.016)^{* *}\end{array}$ \\
\hline Tenure & $\begin{array}{c}0.039 \\
(0.017)^{*}\end{array}$ & $\begin{array}{c}0.18 \\
(0.016)^{* * *}\end{array}$ & $\begin{array}{c}-0.063 \\
(0.018)^{* *}\end{array}$ \\
\hline Tenure-squared & $\begin{array}{c}0.018 \\
(0.026)\end{array}$ & $\begin{array}{c}0.041 \\
(0.019)^{*}\end{array}$ & $\begin{array}{c}-0.079 \\
(0.018)^{* * *}\end{array}$ \\
\hline Job Performance & $\begin{array}{c}0.085 \\
(0.011)^{* * *}\end{array}$ & - & $\begin{array}{c}0.44 \\
(0.0095)^{* * * *}\end{array}$ \\
\hline Justice & $\begin{array}{c}0.20 \\
(0.0081)^{* * *} \\
\end{array}$ & $\begin{array}{c}0.29 \\
(0.011)^{* * *}\end{array}$ & - \\
\hline LMX & - & $\begin{array}{c}0.14 \\
(0.011)^{* * *} \\
\end{array}$ & $\begin{array}{c}0.55 \\
(0.0071)^{* * * *}\end{array}$ \\
\hline $\begin{array}{l}\text { Job Performance } x \\
\text { Tenure }\end{array}$ & $\begin{array}{l}-0.010 \\
(0.016) \\
\end{array}$ & - & $\begin{array}{c}0.21 \\
(0.013)^{* * *} \\
\end{array}$ \\
\hline Justice $x$ Tenure & $\begin{array}{c}-0.25 \\
(0.015)^{* * *}\end{array}$ & $\begin{array}{c}-0.29 \\
(0.017)^{* * * *}\end{array}$ & -- \\
\hline LMX x Tenure & - & $\begin{array}{c}0.046 \\
(0.015)^{* *}\end{array}$ & $\begin{array}{c}0.18 \\
(0.012)^{* * *}\end{array}$ \\
\hline \multicolumn{4}{|c|}{ Variance Components } \\
\hline Intercept & 0.25515 & 0.41313 & 0.24553 \\
\hline Level-1 Variance & 0.659047 & 0.39266 & 0.40017 \\
\hline $\begin{array}{l}\text { \% Level-1 Variance } \\
\text { Explained }\end{array}$ & $8 \%$ & $24 \%$ & $48 \%$ \\
\hline
\end{tabular}

Notes: $* \mathrm{p}<.05 ; * * \mathrm{p}<.01 ; * * * \mathrm{p}<.001$. Analyses based on 21,000 level-1 units and 1000 level-2 units, representing 21 time periods ( $=7$ years of data). The independent variables are from the time period prior to $(=4$ months earlier) than the dependent variables. For all of the above analyses, terms are mean centered before computing the interactions, and all terms are group-mean centered in the model. Percent explained is relative to the null model, which predicts the dependent variable with only an intercept modeled with a random effect. All models had significant level-2 variance at $\mathrm{p}<.001$. 
TABLE 4

Effects of Changes in Justice and Performance on LMX

\begin{tabular}{|c|c|}
\hline \multicolumn{2}{|l|}{ Fixed Effects } \\
\hline & Coefficient \\
\hline Intercept & $\begin{array}{c}-0.076 \\
(0.017)^{* * *}\end{array}$ \\
\hline Tenure & $\begin{array}{l}-0.0090 \\
(0.017)\end{array}$ \\
\hline Tenure-squared & $\begin{array}{c}0.011 \\
(0.028)\end{array}$ \\
\hline Lagged Justice (t-1) & $\begin{array}{l}-0.046 \\
(0.0091)\end{array}$ \\
\hline $\begin{array}{l}\text { Change in Justice } \\
\text { (from t-2 to t-1) }\end{array}$ & $\begin{array}{c}0.42 \\
(0.011)^{* * *}\end{array}$ \\
\hline Lagged Performance (t-1) & $\begin{array}{c}0.31 \\
(0.014)^{* * *}\end{array}$ \\
\hline $\begin{array}{l}\text { Change in Performance } \\
\quad \text { (from } t-2 \text { to } t-1)\end{array}$ & $\begin{array}{c}-0.20 \\
(0.0096)^{* * *}\end{array}$ \\
\hline \multicolumn{2}{|c|}{ Variance Components } \\
\hline Intercept & $0.26696 * * *$ \\
\hline Level-1 & 0.60967 \\
\hline $\begin{array}{c}\text { \% Level-1 Variance } \\
\text { Explained }\end{array}$ & $14 \%$ \\
\hline
\end{tabular}

Notes: There are 22 time periods. These analyses predict the dependent variable at time t. The "Lagged" variable in each analysis refers to the level of the noted variable from the prior time period (i.e., at $\mathrm{t}-1)$. The change in the independent variable reflects the change from ( $\mathrm{t}-1)$ to $(\mathrm{t}-2)$. 


\section{APPENDIX A}

\section{Analysis of Dyadic Tenure Means and Standard Deviation}

\begin{tabular}{|c|c|c|c|}
\hline Study & $\mathbf{N}$ & Mean & SD \\
\hline Ansari, Aafaqi, \& Ahmad (2009) & 411 & 4.36 & 3.60 \\
\hline Ansari, Bui, Utama, \& Aafaqi (2007) & 225 & 2.45 & 2.33 \\
\hline Bluhm (2012) & 387 & 1.10 & 1.30 \\
\hline Burton, Sablynski, \& Sekiguchi (2008) & 258 & 4.37 & 5.01 \\
\hline Cheng, Lu, Chang, \& Johnstone (2013) & 206 & 3.62 & 4.12 \\
\hline Duarte, Goodson, \& Klich (1994) & 367 & 1.51 & 1.34 \\
\hline Engle \& Lord (1997) & 76 & 2.25 & na \\
\hline Harris (2004) & 193 & 2.35 & na \\
\hline Hu \& Liden (2013) & 275 & 2.33 & 1.74 \\
\hline Huang, Chan, Lam, \& Nan (2010) & 493 & 1.28 & na \\
\hline Huang \& Iun (2006) & 205 & 3.75 & na \\
\hline Hwa, Ansari, \& Jantan (2005) & 229 & 5.00 & 4.26 \\
\hline Klein \& Snell (1994) & 55 & 2.50 & na \\
\hline Kunze \& Phillips (2011) & 278 & 2.09 & 2.78 \\
\hline Lam (2006) & 209 & 1.01 & 1.07 \\
\hline Landry \& Vandenberghe (2009) & 240 & 2.38 & 3.24 \\
\hline Martinko, Moss, Douglas, \& Borkowski (2007) & 45 & 3.42 & 3.02 \\
\hline Martinko, Moss, Douglas, \& Borkowski (2007) & 146 & 4.33 & 3.7 \\
\hline Maslyn \& Uhl-Bien (2001) & 153 & 0.84 & 0.77 \\
\hline Meiners \& Boster (2012) & 89 & 3.59 & 3.98 \\
\hline Moss, Sanchez, Brumbaugh, \& Borkowski (2009) & 183 & 4.50 & 5.08 \\
\hline Richards \& Hackett (2012) & 150 & 5.18 & 4.36 \\
\hline Sekiguchi, Burton, \& Sablynski (2008) & 125 & 2.27 & 1.49 \\
\hline Sekiguchi, Burton, \& Sablynski (2008) & 242 & 4.58 & 5.14 \\
\hline Sin, Nahrgang, \& Morgeson (2009) & 98 & 6.64 & 6.61 \\
\hline Sparrowe \& Liden (2005) & 212 & 2.33 & 2.83 \\
\hline Sue-Chan, Chen, \& Lam (2011) & 270 & 1.51 & 2.34 \\
\hline Sun \& Anderson (2012) & 100 & 4.60 & na \\
\hline Sun, Zhang, Qi, \& Chen (2012) & 385 & 4.11 & 4.11 \\
\hline Tse, Lam, Lawrence, \& Huang (2013) & 128 & 5.07 & 8.24 \\
\hline Uhl-Bien \& Maslyn (2003) & 280 & 0.83 & 0.87 \\
\hline Wallis, Yammarino, \& Feyerherm (2011) & 10 & 2.82 & 1.08 \\
\hline Wang, Sui, Luthans, Wang, \& Wu (2012) & 794 & 3.30 & 3.70 \\
\hline White, Campbell, \& Kacmar (2012) & 251 & 9.38 & 11.41 \\
\hline Zhang, Wang, \& Shi (2012) & 165 & 0.95 & 0.52 \\
\hline Mean & 227 & 3.17 & 3.37 \\
\hline Weighted Mean & & 3.02 & 3.33 \\
\hline
\end{tabular}

Notes: Studies listed twice indicate that values were taken from different samples reported in the same paper. 


\section{APPENDIX B}

\section{Simulation Approach}

\section{Step 1: Generate Initial Tenure ( $T)$}

\section{$\mathrm{T}_{\mathrm{i}, 1}=-0.907$}

[Note: The subscript i denotes the simulated person. The second subscript represents the time period; for generating the data initially, we create data for time period 1.]

\section{Step 2: Generate Initial Values of Other Variables}

2a: $\quad$ Generate Performance $(\mathrm{P})$

$\mathrm{P}_{\mathrm{i}, 1}=\mathrm{r}(\mathrm{T}, \mathrm{P}) * \mathrm{~T}_{\mathrm{i} 1}+\operatorname{Sqrt}\left[1-\mathrm{r}(\mathrm{T}, \mathrm{P})^{2}\right] * \operatorname{NRnd}(0,1)$

[Notes: $r(T, P)$ represents the correlation between tenure and performance.

NRnd $(0,1)$ represents a normally distributed, random variable, from a distribution with a mean of 0 and a standard deviation of 1 . Sqrt represent a square root function.]

2b: $\quad$ Generate Justice $(\mathrm{J})$

$$
\begin{aligned}
& \mathbf{R}_{\mathbf{x x}}=\left[\begin{array}{cc}
1 & \mathrm{r}(\mathrm{T}, \mathrm{P}) \\
\mathrm{r}(\mathrm{T}, \mathrm{P}) & 1
\end{array}\right] \\
& \mathbf{R}_{\mathbf{x y}}=\left[\begin{array}{l}
\mathrm{r}(\mathrm{T}, \mathrm{J}) \\
\mathrm{r}(\mathrm{P}, \mathrm{J})
\end{array}\right] \\
& \mathbf{B}=\left[\mathbf{R}_{\mathbf{x x}}^{\prime} \mathbf{R}_{\mathbf{x x}}\right]^{-1} \mathbf{R}_{\mathbf{x y}} \\
& \mathrm{R}^{2}=\left[\mathbf{B}^{\prime} \mathbf{R}_{\mathbf{x y}}\right] \\
& \mathrm{J}_{\mathrm{i}, 1}=\mathrm{B}_{1} * \mathrm{~T}_{\mathrm{i}, 1}+\mathrm{B}_{2} * \mathrm{P}_{\mathrm{i}, 1}+\operatorname{Sqrt}\left[\left(1-\mathrm{R}^{2}\right)\right] * \operatorname{NRnd}(0,1)
\end{aligned}
$$

[Note: Variables in bold text refers to matrices, whereas plain-text variables are single values. $B_{N}$ refers to the $\mathrm{N}_{\text {th }}$ element in the $\mathbf{B}$ matrix.]

2c: Generate LMX

$$
\begin{aligned}
\mathbf{R}_{\mathbf{x x}}= & {\left[\begin{array}{ccc}
1 & \mathrm{r}(\mathrm{T}, \mathrm{P}) & \mathrm{r}(\mathrm{T}, \mathrm{J}) \\
\mathrm{r}(\mathrm{T}, \mathrm{P}) & 1 & \mathrm{r}(\mathrm{P}, \mathrm{J}) \\
\mathrm{r}(\mathrm{T}, \mathrm{J}) & \mathrm{r}(\mathrm{P}, \mathrm{J}) & 1
\end{array}\right] } \\
& \mathbf{R}_{\mathbf{x y}}=\left[\begin{array}{c}
\mathrm{r}(\mathrm{T}, \mathrm{LMX}) \\
\mathrm{r}(\mathrm{P}, \mathrm{LMX}) \\
\mathrm{r}(\mathrm{J}, \mathrm{LMX})
\end{array}\right] \\
& \mathbf{B}_{=}\left[\mathbf{R}_{\mathbf{x x}}^{\prime} \mathbf{R}_{\mathbf{x x}}\right]^{-1} \mathbf{R}_{\mathbf{x y}} \\
& \mathrm{R}^{2}=\left[\mathbf{B}^{\prime} \mathbf{R}_{\mathbf{x y}}\right] \\
& \mathrm{LMX}_{\mathrm{i}, 1}=\mathrm{B}_{1} * \mathrm{~T}_{\mathrm{i}, 1}+\mathrm{B}_{2} * \mathrm{P}_{\mathrm{i}, 1}+\mathrm{B}_{3} * \mathrm{~J}_{\mathrm{i}, 1}+\operatorname{Sqrt}\left[\left(1-\mathrm{R}^{2}\right)\right] * \operatorname{NRnd}(0,1)
\end{aligned}
$$




\section{Step 3: Age Data}

3a: Increase tenure from (t-1) to $(\mathrm{t})$

$$
\mathrm{T}_{\mathrm{i}, \mathrm{t}}=\mathrm{T}_{\mathrm{i}, \mathrm{t}-1)}+0.1001
$$

[Note: Data from (t-1) was generated in the previous step, either Step 2 above, or a previous iteration of Step 3.]

3b: Generate Performance (for time $t$ )

$$
\begin{aligned}
& \mathbf{R}_{\mathbf{x x}}=\left[\begin{array}{cccc}
1 & \mathrm{r}(\mathrm{P}, \mathrm{J}) & \mathrm{r}(\mathrm{P}, \mathrm{LMX}) & \mathrm{r}(\mathrm{P}, \mathrm{T}) \\
\mathrm{r}(\mathrm{P}, \mathrm{J}) & 1 & \mathrm{r}(\mathrm{J}, \mathrm{LMX}) & \mathrm{r}(\mathrm{J}, \mathrm{T}) \\
\mathrm{r}(\mathrm{P}, \mathrm{LMX}) & \mathrm{r}(\mathrm{J}, \mathrm{LMX}) & 1 & \mathrm{r}(\mathrm{LMX}, \mathrm{T}) \\
\mathrm{r}(\mathrm{P}, \mathrm{T}) & \mathrm{r}(\mathrm{J}, \mathrm{T}) & \mathrm{r}(\mathrm{LMX}, \mathrm{T}) & 1
\end{array}\right] \\
& \mathbf{R}_{\mathbf{x y}}=\left[\begin{array}{c}
\mathrm{r}\left(\mathrm{P}_{(t-1)}, \mathrm{P}_{t}\right) \\
\mathrm{r}\left(\mathrm{J}_{(t-1)}, \mathrm{P}_{t}\right) \\
\mathrm{r}\left(\mathrm{LMX}_{(t-1)}, \mathrm{P}_{t}\right) \\
\mathrm{r}(\mathrm{T}, \mathrm{P})
\end{array}\right] \\
& \mathbf{B}=\left[\mathbf{R}_{\mathrm{xx}}^{\prime} \mathbf{R}_{\mathrm{xx}}\right]^{-1} \mathbf{R}_{\mathrm{xy}} \\
& \mathrm{R}^{2}=\left[\mathbf{B}^{\prime} \mathbf{R}_{\mathbf{x y}}\right] \\
& \mathrm{P}_{\mathrm{i}, \mathrm{t}}=\mathrm{B}_{1} * \mathrm{P}_{\mathrm{i},(\mathrm{t}-1)}+\mathrm{B}_{2} * \mathrm{~J}_{\mathrm{i},(\mathrm{t}-1)}+\mathrm{B}_{3} * \mathrm{LMX}_{\mathrm{i},(\mathrm{t}-1)}+\mathrm{B}_{4} * \mathrm{~T}_{\mathrm{i}, \mathrm{t}}+\operatorname{sqrt}\left[\left(1-\mathrm{R}^{2}\right)\right] * \\
& \operatorname{NRnd}(0,1)
\end{aligned}
$$

[Note: Correlations without subscript (i.e., $r(\mathrm{P}, \mathrm{J})$ represent the cross-sectional correlation. Correlations with the subscripts $(\mathrm{t}-1)$ and $(\mathrm{t})$ represent correlations across time.]

3c: Generate Justice (for time $\mathrm{t}$ )

$$
\begin{aligned}
\mathbf{R}_{\mathbf{x x}}= & {\left[\begin{array}{ccccc}
1 & \mathrm{r}(\mathrm{P}, \mathrm{J}) & \mathrm{r}(\mathrm{P}, \mathrm{LMX}) & \mathrm{r}(\mathrm{P}, \mathrm{T}) & \mathrm{r}\left(\mathrm{P}_{(t-1)}, \mathrm{P}_{t}\right) \\
\mathrm{r}(\mathrm{P}, \mathrm{J}) & 1 & \mathrm{r}(\mathrm{J}, \mathrm{LMX}) & \mathrm{r}(\mathrm{J}, \mathrm{T}) & \mathrm{r}\left(\mathrm{J}_{(t-1)}, \mathrm{P}_{t}\right) \\
\mathrm{r}(\mathrm{P}, \mathrm{LMX}) & \mathrm{r}(\mathrm{J}, \mathrm{LMX}) & 1 & \mathrm{r}(\mathrm{LMX}, \mathrm{T}) & \mathrm{r}\left(\mathrm{LMX}_{(t-1)}, \mathrm{P}_{t}\right) \\
\mathrm{r}(\mathrm{P}, \mathrm{T}) & \mathrm{r}(\mathrm{J}, \mathrm{T}) & \mathrm{r}(\mathrm{LMX}, \mathrm{T}) & 1 & \mathrm{r}\left(\mathrm{T}_{i, t}, \mathrm{P}\right) \\
\mathrm{r}\left(\mathrm{P}_{(t-1)}, \mathrm{P}_{t}\right) & \mathrm{r}\left(\mathrm{J}_{(t-1)}, \mathrm{P}_{t}\right) & \mathrm{r}\left(\mathrm{LMX}_{(t-1)}, \mathrm{P}_{t}\right) & \mathrm{r}\left(\mathrm{T}_{i, t}, \mathrm{P}\right) & 1
\end{array}\right] } \\
& \mathbf{R}_{\mathbf{x y}}=\left[\begin{array}{c}
\mathrm{r}\left(\mathrm{P}_{(t-1)}, \mathrm{J}_{t}\right) \\
\mathrm{r}\left(\mathrm{J}_{(t-1)}, \mathrm{J}_{t}\right) \\
\mathrm{r}\left(\mathrm{LMX}_{(t-1)}, \mathrm{J}_{t}\right) \\
\mathrm{r}(\mathrm{T}, \mathrm{J}) \\
\mathrm{r}\left(\mathrm{P}_{,}, \mathrm{J}\right)
\end{array}\right] \\
& \mathbf{B}^{-1}=\left[\mathbf{R}_{\mathbf{x x}}^{\prime} \mathbf{R}_{\mathbf{x x}}\right]^{-1} \mathbf{R}_{\mathbf{x y}} \\
\mathrm{R}^{2}=\left[\mathbf{B}^{\prime} \mathbf{R}_{\mathbf{x y}}\right] & \mathrm{J}_{\mathrm{i}, \mathrm{t}}=\mathrm{B}_{1} * \mathrm{P}_{\mathrm{i},(\mathrm{t}-1)}+\mathrm{B}_{2} * \mathrm{~J}_{\mathrm{i},(\mathrm{t}-1)}+\mathrm{B}_{3} * \mathrm{LMX}_{\mathrm{i},(\mathrm{t}-1)}+\mathrm{B}_{4} * \mathrm{~T}_{\mathrm{i}, \mathrm{t}}+\mathrm{B}_{5} * \mathrm{P}_{\mathrm{i}, \mathrm{t}}+\operatorname{sqrt}\left[\left(1-\mathrm{R}^{2}\right)\right] * \\
& \mathrm{NRnd}(0,1)
\end{aligned}
$$


3d: Generate LMX (for time t)

$$
\begin{aligned}
& \mathbf{R}_{\mathbf{x x}}= \\
& {\left[\begin{array}{cccccc}
1 & \mathrm{r}(\mathrm{P}, \mathrm{J}) & \mathrm{r}(\mathrm{P}, \mathrm{LMX}) & \mathrm{r}(\mathrm{P}, \mathrm{T}) & \mathrm{r}\left(\mathrm{P}_{(t-1)}, \mathrm{P}_{t}\right) & \mathrm{r}\left(\mathrm{P}_{(t-1)}, \mathrm{J}_{t}\right) \\
\mathrm{r}(\mathrm{P}, \mathrm{J}) & 1 & \mathrm{r}(\mathrm{J}, \mathrm{LMX}) & \mathrm{r}(\mathrm{J}, \mathrm{T}) & \mathrm{r}\left(\mathrm{J}_{(t-1)}, \mathrm{P}_{t}\right) & \mathrm{r}\left(\mathrm{J}_{(t-1)}, \mathrm{J}_{t}\right) \\
\mathrm{r}(\mathrm{P}, \mathrm{LMX}) & \mathrm{r}(\mathrm{J}, \mathrm{LMX}) & 1 & \mathrm{r}(\mathrm{LMX}, \mathrm{T}) & \mathrm{r}\left(\mathrm{LMX}_{(t-1)}, \mathrm{P}_{t}\right) & \mathrm{r}\left(\mathrm{LMX}_{(t-1)}, \mathrm{J}_{t}\right) \\
\mathrm{r}(\mathrm{P}, \mathrm{T}) & \mathrm{r}(\mathrm{J}, \mathrm{T}) & \mathrm{r}(\mathrm{LMX}, \mathrm{T}) & 1 & \mathrm{r}\left(\mathrm{T}_{i, t}, \mathrm{P}\right) & \mathrm{r}(\mathrm{T}, \mathrm{J}) \\
\mathrm{r}\left(\mathrm{P}_{(t-1)}, \mathrm{P}_{t}\right) & \mathrm{r}\left(\mathrm{J}_{(t-1)}, \mathrm{P}_{t}\right) & \mathrm{r}\left(\mathrm{LMX}_{(t-1)}, \mathrm{P}_{t}\right) & \mathrm{r}\left(\mathrm{T}_{i, t}, \mathrm{P}\right) & 1 & \mathrm{r}(\mathrm{P}, \mathrm{J}) \\
\mathrm{r}\left(\mathrm{P}_{(t-1)}, \mathrm{J}_{t}\right) & \mathrm{r}\left(\mathrm{J}_{(t-1)}, \mathrm{J}_{t}\right) & \mathrm{r}\left(\mathrm{LMX}_{(t-1)}, \mathrm{J}_{t}\right) & \mathrm{r}(\mathrm{T}, \mathrm{J}) & \mathrm{r}(\mathrm{P}, \mathrm{J}) & 1
\end{array}\right]} \\
& \mathbf{R}_{\mathbf{x y}}=\left[\begin{array}{c}
\mathrm{r}\left(\mathrm{P}_{(t-1)}, \mathrm{LMX}_{t}\right) \\
\mathrm{r}\left(\mathrm{J}_{(t-1)}, \mathrm{LMX}_{t}\right) \\
\mathrm{r}\left(\mathrm{LMX}_{(t-1)}, \mathrm{LMX}_{t}\right) \\
\mathrm{r}(\mathrm{T}, \mathrm{LMX}) \\
\mathrm{r}(\mathrm{P}, \mathrm{LMX}) \\
\mathrm{r}(\mathrm{J}, \mathrm{LMX})
\end{array}\right]
\end{aligned}
$$

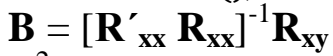

$$
\begin{aligned}
& \mathrm{R}^{2}=\left[\mathbf{B}^{\prime} \mathbf{R}_{\mathbf{x y}}\right] \\
& \mathrm{LMX}_{\mathrm{i}, \mathrm{t}}=\mathrm{B}_{1} * \mathrm{P}_{\mathrm{i},(\mathrm{t}-1)}+\mathrm{B}_{2} * \mathrm{~J}_{\mathrm{i}, \mathrm{t}-1)}+\mathrm{B}_{3} * \mathrm{LMX}_{\mathrm{i},(\mathrm{t}-1)}+\mathrm{B}_{4} * \mathrm{~T}_{\mathrm{i}, \mathrm{t}}+\mathrm{B}_{5} * \mathrm{P}_{\mathrm{i}, \mathrm{t}}+\mathrm{B}_{6} * \mathrm{~J}_{\mathrm{i}, \mathrm{t}}+ \\
& \operatorname{sqrt}\left[\left(1-\mathrm{R}^{2}\right)\right] * \operatorname{NRnd}(0,1)
\end{aligned}
$$

Step 4: Repeat step 3 for as many time periods as desired. 